Published in final edited form as:

Nat Immunol. 2018 May ; 19(5): 497-507. doi:10.1038/s41590-018-0083-5.

\title{
c-Maf controls immune responses by regulating disease-specific gene networks and repressing IL-2 in CD4+ $T$ cells
}

\author{
Leona Gabryšová ${ }^{1}$, Marisol Alvarez-Martinez ${ }^{1}$, Raphaëlle Luisier ${ }^{2}$, Luke S. Cox ${ }^{1}$, Jan \\ Sodenkamp ${ }^{3}$, Caroline Hosking ${ }^{3}$, Damián Pérez-Mazliah ${ }^{3}$, Charlotte Whicher ${ }^{1}$, Yashaswini \\ Kannan $^{4}$, Krzysztof Potempa ${ }^{1}$, Xuemei Wu ${ }^{1}$, Leena Bhaw ${ }^{5}$, Hagen Wende ${ }^{6}$, Michael H. \\ Sieweke $^{7,8}$, Greg Elgar ${ }^{5}$, Mark Wilson ${ }^{4}$, James Briscoe ${ }^{9}$, Vicki Metzis $^{9}$, Jean Langhorne ${ }^{3}$, \\ Nicholas M. Luscombe ${ }^{2,10}$, and Anne O'Garra ${ }^{1,11,{ }^{*}}$ \\ ${ }^{1}$ The Francis Crick Institute, Laboratory of Immunoregulation and Infection, Midland Road, \\ London, UK \\ ${ }^{2}$ The Francis Crick Institute, Computational Biology Laboratory, Midland Road, London, UK \\ ${ }^{3}$ The Francis Crick Institute, Malaria Laboratory, Midland Road, London, UK \\ ${ }^{4}$ The Francis Crick Institute, Helminth Immunology Laboratory, Midland Road, London, UK \\ ${ }^{5}$ The Francis Crick Institute, Advanced Sequencing Facility Laboratory, Midland Road, London, \\ UK \\ ${ }^{6}$ Heidelberg University, Institute of Pharmacology, Heidelberg, Germany \\ ${ }^{7}$ Aix Marseille Univ, CNRS, INSERM, CIML, Marseille, France \\ ${ }^{8}$ Max-Delbrück-Centrum für Molekulare Medizin in der Helmholtzgemeinschaft (MDC), Robert- \\ Rössle-Strasse 10, 13125 Berlin, Germany \\ ${ }^{9}$ The Francis Crick Institute, Developmental Dynamics Laboratory, Midland Road, London, UK
}

\footnotetext{
Users may view, print, copy, and download text and data-mine the content in such documents, for the purposes of academic research, subject always to the full Conditions of use:http://www.nature.com/authors/editorial_policies/license.html\#terms

`Please address correspondence to: Anne O'Garra, The Francis Crick Institute, Laboratory of Immunoregulation and Infection, 1 Midland Road, London; anne.ogarra@crick.ac.uk.

Author Contributions

L.G. co-designed the study, executed the experiments and interpreted and analyzed the data and co-wrote the paper; M.A.M. analyzed the ATAC-seq, ChIP-seq and RNA-seq data and contributed towards the writing of the paper; R.L. interpreted and analyzed the RNAseq data and contributed towards writing of the paper; L.S.C. executed and helped design the in vitro experiments with c-Maf-deficient $\mathrm{CD}^{+}{ }^{+} \mathrm{T}$ cells and controls, and analyzed the data; J.S. and C.H. helped execute and interpret malaria experiments; D.P-M. contributed data for Supplementary Figure 3; C.W. helped execute EAE experiments; Y.K. and M.W. helped execute and interpret allergy

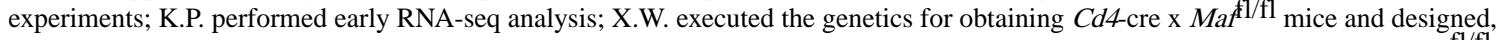
performed all screening and quality control; L.B. performed processing and trouble-shooting for RNA-seq; H.W. constructed Maf fl/fl mice and provided feedback on the study; M.H.S. provided feedback and suggestions for the study; G.E. supervised early RNA-seq data analysis; J.L. provided the malaria model expertise and feedback on the study; V.M. and J.B. provided expert advice and input on the ATAC-seq analysis; N.M.L. provided expert advice and input on the RNA-seq analysis and directed the integrated analysis of ATAC-seq, ChIP-seq and RNA-seq; A.O.G. co-designed the study, interpreted and analyzed the data and co-wrote the paper.

Author information

Reprints and permissions information is available at www.nature.com/reprints.

Competing financial interests

The authors declare no competing financial interests.
} 
${ }^{10}$ UCL Genetics Institute, Department of Genetics, Evolution and Environment, University College London, Gower Street, London, UK

${ }^{11}$ National Heart and Lung Institute, Imperial College London, London, UK

\section{Abstract}

The transcription factor c-Maf induces the anti-inflammatory cytokine IL-10 in CD4 ${ }^{+} \mathrm{T}$ cells in vitro. However, the global effects of c-Maf on diverse immune responses in vivo are unknown. Here we show that c-Maf regulates IL-10 production in $\mathrm{CD}^{+} \mathrm{T}$ cells in $\mathrm{T}_{\mathrm{H}} 1$ (malaria), $\mathrm{T}_{\mathrm{H}} 2$ (allergy) and $\mathrm{T}_{\mathrm{H}} 17$ (autoimmunity) disease models in vivo. Although CD4-targeted Maf-deficient mice showed greater pathology in $\mathrm{T}_{\mathrm{H}} 1$ and $\mathrm{T}_{\mathrm{H}} 2$ responses, $\mathrm{T}_{\mathrm{H}} 17$-mediated pathology was reduced, with accompanying decreased $\mathrm{T}_{\mathrm{H}} 17$ and increased Foxp $3^{+}$regulatory $\mathrm{T}$ cells. Bivariate genomic footprinting elucidated the c-Maf transcription factor network, including enhanced NFAT activity, leading to the identification and validation of c-Maf as a negative regulator of IL-2. Decreased Rorc resulting from c-Maf deficiency was dependent on IL-2, explaining the in vivo observations. Thus, c-Maf is a positive and negative regulator of cytokine gene expression, with context-specific effects that allow each immune response to occur in a controlled yet effective manner.

\section{Introduction}

The immune response is under strict control to regulate the production of inflammatory mediators to control infection with minimum damage to the host. $\mathrm{CD}^{+} \mathrm{T}$ cell subsets including $\mathrm{T}_{\mathrm{H}} 1, \mathrm{~T}_{\mathrm{H}} 2$ and $\mathrm{T}_{\mathrm{H}} 17$ cells are critical for eradication of specific pathogens 1 , but if uncontrolled, can contribute to immune pathologies, either during infection or immunemediated diseases2,3. A number of regulatory mechanisms are in place to control inappropriate or excessive immune responses, including the production of the antiinflammatory cytokine IL-10 (ref. 4) and Foxp3-expressing CD4+ regulatory $\left(\mathrm{T}_{\text {reg }}\right.$ ) cells5. Although distinct molecular pathways direct the development of different effector and regulatory $\mathrm{CD}^{+}{ }^{+} \mathrm{T}$ cells, $\mathrm{IL}-10$ is produced by all $\mathrm{CD} 4^{+} \mathrm{T}$ cell subsets and is therefore not a subset-specific cytokine 4 . Whether IL-10 production is regulated by lineage-specific mechanisms, or whether a common transcription factor (TF) controls IL-10 in all CD4 ${ }^{+} \mathrm{T}$ cell subsets is unclear. Many TFs6-20 have been shown to modulate $I 110$ gene expression including the activator protein (AP)-1 superfamily member c-Maf7,16,19-21. c-Maf functions to control an array of biological processes including lens and bone development, apoptosis, oncogenesis, and the immune response22. Although c-Maf has been shown to positively regulate $I 110$ gene expression in vitro6,7,16,21, its effects on $I 110$ and global gene expression across different immune responses in vivo are unknown.

Here we report that c-Maf regulates IL-10 in vivo in $\mathrm{CD} 4{ }^{+} \mathrm{T}$ cells from $\mathrm{T}_{\mathrm{H}} 1$ (malaria), $\mathrm{T}_{\mathrm{H}} 2$ (allergy) and $\mathrm{T}_{\mathrm{H}} 17$ (autoimmunity) disease models, but has context-specific effects on these immune responses, over and above effects on IL-10. Using genomic approaches, we found that Maf-deficient $\mathrm{CD} 4^{+} \mathrm{T}$ cells showed significant changes in transcriptional activity, including enhanced NFAT activity, leading to the identification and validation of c-Maf as a negative regulator of IL-2. This provided an explanation for the context-specific effects of c- 
Maf deficiency on the immune responses, which included decreased $\mathrm{T}_{\mathrm{H}} 17$ cells, increased Foxp $3^{+} \mathrm{T}_{\text {reg }}$ cells and reduced autoimmune pathology in vivo.

\section{Results}

\section{Maf and I/10 expression correlate in all $\mathrm{T}_{\mathrm{H}}$ and $\mathrm{T}_{\text {reg }}$ cell subsets}

To identify candidate TFs regulating the expression of $I 110$ in different $\mathrm{CD}^{+} \mathrm{T}$ cell subsets, in vitro differentiated $\mathrm{T}_{\mathrm{H}} 1, \mathrm{~T}_{\mathrm{H}} 1+\mathrm{IL}-27$ (ref. 23 ), $\mathrm{T}_{\mathrm{H}} 2, \mathrm{~T}_{\mathrm{H}} 17$, IL-10 only producing VitD3+Dex3 (ref. 24) $\mathrm{T}$ cells and ex vivo derived Foxp $3^{+} \mathrm{T}_{\text {reg }}$ cells were profiled by RNAseq (Fig. 1a-d). We correlated the expression of TFs to $1110 \mathrm{mRNA}$ across all $\mathrm{T}_{\mathrm{H}}$ and $\mathrm{T}_{\text {reg }}$ cell subsets (Fig. 1e; Supplementary Table 1). Maf which was upregulated upon differentiation (Supplementary Fig. 1), was the strongest candidate for a positive regulator of IIIO (Fig. 1e and f) against other TFs previously associated with IL-10 (ref. 6-17,21,25) (Fig. 1e). In contrast, no correlation between Maf expression and the hallmark cytokines Ifng or II4 was observed but, as expected, these effector cytokines showed tight correlation with expression of the $\mathrm{T}_{\mathrm{H}} 1$ and $\mathrm{T}_{\mathrm{H}} 2$ hallmark TFs, $T b \times 21$ and Gata3, respectively (Fig. 1f). Thus, c-Maf may function as a common regulator of IL-10 in $\mathrm{CD}^{+} \mathrm{T}$ cells regardless of the T cell subset.

\section{c-Maf deficiency in $\mathrm{CD4}^{+} \mathrm{T}$ cells affects susceptibility to disease in a context-specific manner}

Having identified c-Maf as the strongest candidate TF regulator of IL-10, we next sought to test whether c-Maf is a common regulator of IL-10 in vivo and to what extent c-Maf affects the immune response and associated pathologies. To this end, we investigated the effect of CD4-targeted Maf deletion in mouse models of malaria26 ( $\left.\mathrm{T}_{\mathrm{H}} 1\right)$, house dust mite (HDM) allergy27 $\left(\mathrm{T}_{\mathrm{H}} 2\right)$ and experimental autoimmune encephalitis (EAE)28 $\left(\mathrm{T}_{\mathrm{H}} 17\right)$, encapsulating a spectrum of immune responses (Fig. 2a-c). In the malaria model, $\mathrm{Maf}{ }^{\mathrm{fl} / \mathrm{fl}} \mathrm{Cd}$-cre mice showed increased acute-phase pathology, with significant weight loss and decline in temperature, but little to no effect on parasite load as compared to Maf $f^{f / f l}$ control mice (Fig. 2d). Similarly, in the HDM allergy model, $M a f^{f l / f l} C d 4$ cre mice had increased total number of cells in the bronchoalveolar lavage, mostly consisting of eosinophils, and increased lung pathology characterised by greater mucus and inflammation scores as compared to Mafl/f1 control mice (Fig. 2e). Maf ${ }^{\text {fl/fl }} \mathrm{Cd}$-cre mice showed reduced pathology in the $\mathrm{T}_{\mathrm{H}} 17 \mathrm{EAE}$ model, as demonstrated by reduced weight loss and clinical score, with overall less advanced disease as compared to $M a f^{f l / f l}$ control mice (Fig. 2f). Our findings thus demonstrate that the disease-associated pathology resulting from CD4-targeted Maf deletion phenocopies that of IL-10 deficiency in malaria26 and is in keeping with IL-10's regulatory role in allergy29. In contrast, Maf deletion in the EAE setting showed the opposite effect to that reported for IL-10 (ref. 30), indicating that c-Maf plays an additional role in $\mathrm{T}_{\mathrm{H}} 17$ responses that contributes towards pathology.

\section{Deciphering c-Maf-driven transcriptional programs within dominant disease-associated immune responses}

To better understand the disease-specific effects of Maf deletion, we performed RNA-seq on purified $\mathrm{CD}^{+}{ }^{+} \mathrm{T}$ cells isolated from spleens, lungs and the central nervous system from the 
three disease models. Hierarchical clustering revealed that the strongest variations in gene expression were driven by each disease (Fig. 3a and Supplementary Data for Computational Methods). However, a clear separation in gene expression in $\mathrm{CD}^{+} \mathrm{T}$ cells from CD4targeted Maf deleted mice versus controls, was not discernible, except in the malaria model (Fig. 3a). Indeed, 78\% of the variance captured by the first two singular value decomposition components, clustered the samples according to the disease-specific immune response as shown by biological pathway analyses (Fig. 3b, c and d; Supplementary Table 2). The fourth component, although accounting for only $3 \%$ of the variance (Fig. 3b, c, and d;

Supplementary Table 2) segregated the samples according to Maf-deficiency, irrespective of the disease (Fig. 3b, and Fig. 3d, right-hand panel). This component was enriched for both down-regulated genes, including transcriptional regulators and immune response genes such as II10, and up-regulated genes, such as genes with proliferative function, E2f1, Runx 3 and II2ra (Fig. 3d). Thus, although the immune response dominates over the deletion of Maf, cMaf does contribute to a small but coherent change in gene expression across all three diseases in vivo that includes $I 110$, corroborating the in vitro findings.

\section{c-Maf regulates II10 expression in $\mathrm{CD}^{+} \mathrm{T}$ cells in vivo with wider disease-specific effects}

Subsequent comparison of differentially expressed genes showed only 48 overlapping genes, as compared to the overall sizable perturbation of 2,635 genes in malaria, 1,073 in HDM allergy and 265 in EAE, many of which were in fact disease-specific, and equally up- or down-regulated, in the absence of c-Maf (Fig. 4a; Supplementary Fig. 2; Supplementary Table 3 and Supplementary Data for Computational Methods). To further characterize the context-specific effects of Maf deletion, the differentially expressed genes belonging to the $\mathrm{TF}$, cytokine and membrane receptor families were interrogated in more detail (Fig. 4b-d; Supplementary Table 4). Twelve percent of the "immune response" genes had known c-Maf relationships. The majority of c-Maf accountable differences in the "non-immune" genes, observed predominantly in malaria, had not previously been recognized (Fig. 4b-d, red lines show known c-Maf interactions). These control general biological processes such as cell cycle (E2f1, E2f12, E2f17 and E2f18) or circadian rhythm (Bhlhe4O)31, but could nonetheless contribute to the net effect of c-Maf on the immune response.

II10 expression was significantly reduced in $\mathrm{CD} 4^{+} \mathrm{T}$ cells across all three diseases in the absence of c-Maf (Fig. 4a and Fig. 4e-g; Supplementary Fig. 2a), as we also demonstrated in IL-27 driven CD4 ${ }^{+} \mathrm{T}$ cells and $\mathrm{T}_{\mathrm{H}} 17$ cells in vitro (Supplementary Fig. 1a). Similarly, IL-10 protein production by $\mathrm{T}_{\mathrm{H}} 1$ and $\mathrm{T}_{\mathrm{H}} 2$ cells, was reduced in response to Maf deletion both in malaria and HDM allergy disease models respectively (Fig. 5a-d). In EAE, however, IL-10 protein was not detectable in $\mathrm{CD}^{+} \mathrm{T}$ cells, in keeping with the low levels of $1110 \mathrm{mRNA}$ observed in this model (Fig. 4g). Although having a uniform role on induction of IL-10, cMaf showed differing effects on hallmark TFs and cytokines as previously demonstrated7,32,33. In malaria, increased $T b \times 21$ expression and IFN- $\gamma$ protein (Fig. 4e; Fig. 5a and b) were observed in the absence of c-Maf, phenocopying the reported effect of II10-deletion on $\mathrm{T}_{\mathrm{H}} 1$ responses 26 . We observed decreased levels of $\mathrm{T}_{\mathrm{H}} 2$-associated genes, including II4 and IIS in HDM allergy in the absence of c-Maf (Fig. 4f). Furthermore, there was a preferential abrogation of IL-4-IL-10 double-producing cells by intracellular cytokine staining (Fig. 5c and d), in keeping with the increased pathology (Fig. 2e). T follicular 
helper $\left(\mathrm{T}_{\mathrm{FH}}\right)$ associated genes, including Bcl6 in the malaria model, and Icos and II21 in both the malaria and HDM allergy models were also decreased (Fig. 4b and c), in line with previous reports of c-Maf positively regulating $\mathrm{T}_{\mathrm{FH}}$ cells 34,35 . However, the increased pathology that we observe in the CD4-targeted c-Maf mice during an acute malaria response cannot be accounted for by decreased $\mathrm{T}_{\mathrm{FH}}$ cells, since deletion of $\mathrm{T}_{\mathrm{FH}}$ cells specifically in $B c l b^{f l / f l} C d 4$ cre mice does not affect pathology in the acute phase of malaria (Supplementary Fig. 3a), but only the parasitemia in the chronic phase36. Moreover, we show also that IL-10, even as late as 15 days post infection, is primarily produced by non$\mathrm{T}_{\mathrm{FH}}$ cells (Supplementary Fig. 3b). In the EAE model, the $\mathrm{T}_{\mathrm{H}} 17$ associated genes (Rorc, III $\mathrm{a}$ and II23r) (Fig. 4d and g) and IL-17A protein were decreased in the absence of c-Maf (Fig. $5 \mathrm{~d}$ and e). We found that in the EAE model, this decrease in the $\mathrm{T}_{\mathrm{H}} 17$ response was accompanied by increased Foxp 3 mRNA expression (Fig. 4g) and increased numbers of Foxp $3^{+} \mathrm{T}_{\text {reg }}$ cells in the absence of c-Maf (Fig. $5 \mathrm{~d}$ and e). Collectively, our findings show that in addition to controlling $\mathrm{T}_{\mathrm{H}} 1$ and $\mathrm{T}_{\mathrm{H}} 2$ responses, c-Maf plays a novel, more dominant role in EAE, over-and-above IL-10 expression, by regulating the balance of $\mathrm{T}_{\mathrm{H}} 17$ (Rorc) and Foxp $3^{+} \mathrm{T}_{\text {reg }}$ cell responses, explaining the discordant disease susceptibility.

\section{The context specificity of c-Maf on the immune response is driven by both direct and indirect mechanisms}

To identify the molecular mechanisms whereby c-Maf affects gene regulation in $\mathrm{CD} 4^{+} \mathrm{T}$ cells in vivo, we used Assay for Transposase-Accessible Chromatin using sequencing (ATAC-seq) to reveal functionally active genomic regions. Consistent with the RNA-seq profile (Fig. 3a), hierarchical clustering of ATAC-seq data revealed that the open chromatin landscape was dominantly driven by each disease, and that a clear separation of chromatin accessibility between control and Maf-deficient $\mathrm{CD} 4^{+} \mathrm{T}$ cells was only observed in the malaria model (Fig. 6a). This could potentially be explained by increased chromatin accessibility in the $M a f^{\text {fl/fl }} C d 4$ cre condition (Fig. 6b), partially explaining the larger number of dysregulated genes in this model (Fig. 4a). Although c-Maf does not itself show evidence of inducing chromatin remodeling (Fig. 6b), de novo motif discovery using MEME-ChIP37 revealed Runx as being enriched in the remodeled loci, suggesting that Runx factors could account for increased open chromatin in malaria through their known interactions with epigenetic modifiers38. However, these changes in chromatin accessibility are not exclusively responsible for the transcriptional changes observed by RNA-seq, since only a small fraction of the differentially expressed genes were associated with altered ATAC-seq peaks in any of the models (Supplementary Fig. 4). Taken together, these data indicate that c-Maf acts via activation and repression of gene expression and the context-specific action is defined by the accessible chromatin landscape dictated by the type of immune response.

We further integrated our RNA-seq and ATAC-seq data with c-Maf ChIP-seq7 and motif data to identify c-Maf target genes, which were corroborated using the Binding and Expression Target Analysis (BETA) software39 (Supplementary Fig. 5; Supplementary Table 5 and Supplementary Data for Computational Methods). Putative c-Maf binding sites were found to be enriched in differentially expressed genes, indicating that c-Maf can have direct effects and is responsible for the significant transcriptional changes seen (Supplementary Table 6). Specifically, the combined evidence of open chromatin coinciding 
with c-Maf binding to the $I 110$ locus confirmed c-Maf as a direct positive regulator of $I 110$ in vivo (Fig. $6 \mathrm{c}$ and d). However, although we found $I 14$ and Rorc to also be direct targets of cMaf, the effect of c-Maf on the expression of Tbx21 and Foxp3 was indirect with no evidence of direct binding to these loci (Fig. $6 \mathrm{c}$ and d; Supplementary Fig. 6). Thus, the observed changes in Rorc vs Foxp3 expression resulting from c-Maf deficiency are likely due to indirect mechanisms.

\section{IL-2 is a c-Maf target}

To identify candidate TFs responsible for the indirect effects of c-Maf, we applied the bivariate genomic footprinting (BaGFoot) software40 to the ATAC-seq data to assess changes in global TF activity, as measured by changes in TF footprint depth and motif flanking accessibility (Fig. 7a; Supplementary Table 7). TF binding site motifs that were significant outliers from the multivariate distribution, presenting differential TF binding in absence of c-Maf compared to control, were predominantly context-specific and more abundant in malaria, than HDM and EAE (Fig. 7a), in line with the expression data (Fig. 4a). Moreover, most of these TF motifs were found to be significantly enriched in the accessible genomic neighbourhood of differentially expressed over the non-differentially expressed genes (Supplementary Table 8) in the different diseases upon c-Maf deletion. The Runx TF, whose motif was enriched in the remodeled loci (Fig. 6b), showed enhanced binding (Fig. 7a) and increased expression (Fig. 3a; 4b-d and Supplementary Table 3) in $M a f^{f l / f l} C d 4$ cre mice exclusively in the malaria model. Further, it showed a more significant effect on differentially expressed genes than c-Maf itself (Supplementary Table 8). Thus, Runx may contribute to the increased pathology in malaria by its reported effects on IFN- $\gamma$ production41. The AP-1 family members BATF, Jund, Jun, and Junb (Fig. 7a;

Supplementary Table 8), which are known to directly interact with c-Maf42, may further contribute to changes in gene expression, including $I 110$ gene regulation9. Bhlhe 40 , a known negative regulator of IL-10 (ref. 43), which we found to be upregulated in Maf-deficient $\mathrm{CD}^{+} \mathrm{T}$ cells (Supplementary Table 3 ), also appeared to additionally contribute to the indirect effects of c-Maf in malaria and HDM allergy as shown by the BaGFoot analysis (Fig. 7a; Supplementary Table 8).

In contrast to the context-specific effects on TFs, the Nfat2 motif showed statistically significant differences in the genome-wide footprints (Fig. 7b) and contributed towards changes in gene expression in all three disease models (Fig. 7a; Supplementary Table 8). Based on the well-known role of NFAT in the regulation of $I 12$ expression44, we now show that both II2 and II2ra are potential direct targets of c-Maf (Fig. 7c). Since IL-2 is known to regulate Foxp $3^{+} \mathrm{T}_{\text {reg }}$ cells5,45 and $\mathrm{T}_{\mathrm{H}} 17$ (ref. 46) cells, we postulated that the observed increase in Foxp $3^{+} \mathrm{T}_{\text {reg }}$ and decreased $\mathrm{T}_{\mathrm{H}} 17$ cells in EAE (Fig. $4 \mathrm{~g}$ and Fig. $5 \mathrm{~d}$ and e) could result from indirect effects of c-Maf on IL-2. To test this and validate the results from our genome network analysis, the effect of c-Maf deletion on $1 / 2$ expression was investigated. Maf-deficient $\mathrm{CD}^{+}{ }^{+} \mathrm{T}$ cells expressed higher levels of $I 12 \mathrm{mRNA}$ as compared to controls under all differentiation conditions, accompanied by a reciprocal decrease in Rorc and an increase in Foxp 3 expression under $\mathrm{T}_{\mathrm{H}} 17$ and induced $\mathrm{T}_{\text {reg }}$ cell ( $\mathrm{iT}_{\text {reg }}$ cell) conditions in vitro, respectively (Fig. 7d). Decreased levels of Rorc observed in Maf-deficient $\mathrm{T}_{\mathrm{H}} 17$ cells were indirect via the action of IL-2, since this effect was abrogated upon neutralization of 
IL-2 (Fig. 7d), resolving previously reported findings which suggested that c-Maf negatively regulates gene expression during $\mathrm{T}_{\mathrm{H}} 17$ differentiation7.

\section{Discussion}

Here we combined comprehensive transcriptional, epigenomic and TF binding analyses of $\mathrm{CD}^{+}{ }^{+} \mathrm{T}$ cells from CD4-targeted Maf-deficient mice to show that c-Maf provides a common mechanism for direct transcriptional regulation of 1110 gene expression in $\mathrm{CD} 4^{+} \mathrm{T}$ cells in vivo in models of $\mathrm{T}_{\mathrm{H}} 1, \mathrm{~T}_{\mathrm{H}} 2$, and $\mathrm{T}_{\mathrm{H}} 17$ responses. Furthermore, we identified a broad context-specific gene expression program regulated by c-Maf, over-and-above its effects on IL-10, which explained the unexpected diverse effects on each disease phenotype. We demonstrated that c-Maf in fact functions by both direct and indirect mechanisms to regulate gene expression and control the effector phenotype in $\mathrm{T}_{\mathrm{H}} 1$ and $\mathrm{T}_{\mathrm{H}} 2$ responses which, in conjunction with IL-10, may reinforce the distinct disease outcomes observed.

In malaria, $\mathrm{T}_{\mathrm{H}} 1$-associated genes are regulated indirectly by a c-Maf-driven gene network that reinforces $\mathrm{T}_{\mathrm{H}} 1$ cell behavior to combat pathology. For example, Bhlhe 40 , a gene associated with circadian rhythm 31 as well as negative regulation of IL-10 (ref. 43), and Runx 3 , which is key for maximal production of IFN- $\gamma 41$ in $\mathrm{T}_{\mathrm{H}} 1$ cells, were found to be upregulated and have increased activity in the absence of c-Maf. In contrast, we found that $\mathrm{T}_{\mathrm{H}}$ 2-associated genes are direct targets of c-Maf, in keeping with its earlier definition as a positive regulator of $\mathrm{T}_{\mathrm{H}} 2$ cytokine gene expression32. However, c-Maf co-regulated IL-10 together with $\mathrm{T}_{\mathrm{H}} 2$-associated genes, thus the decreased IL-4, IL-10 double-producing $\mathrm{T}_{\mathrm{H}} 2$ cells observed in the absence of c-Maf may account for the overall detrimental effect on the disease pathology in the HDM allergy model.

While deletion of c-Maf resulted in increased susceptibility to disease in both the malaria and HDM allergy models, the severity of disease was decreased in EAE despite reduced $I 110$ expression, indicative of additional c-Maf regulated effects. Further inference of c-Maf regulatory networks showed that a proportion of the transcriptional changes seen could be a result of increased NFAT activity observed in Maf-deficient $\mathrm{CD}^{+}{ }^{+} \mathrm{T}$ cells across all disease models. Based on the well-known role of NFAT in the regulation of II2 expression44, and our findings that both Il2 and Il2ra are direct c-Maf targets, we validated the predictions of the regulatory networks to demonstrate the role of c-Maf as a negative regulator of IL-2. Collectively our findings suggest that by negatively regulating $I I 2$ gene expression, c-Maf will have overarching context-specific effects on immune responses, on the one hand, limiting $\mathrm{T}_{\mathrm{H}} 1$ and $\mathrm{T}_{\mathrm{H}} 2$ responses which depend strongly on IL-2, on the other hand allowing the development of a $\mathrm{T}_{\mathrm{H}} 17$ response by regulating Rorc expression and Foxp3 ${ }^{+} \mathrm{T}_{\text {reg }}$ cells. These findings are in apparent contrast to the recent studies using Foxp3-targeted deletion of c-Maf that resulted in reduced Rorc ${ }^{+} \mathrm{Foxp}^{+} \mathrm{T}_{\text {reg }}$ cells19,20, which by nature of the system could not reveal the more global effects of c-Maf on gene expression in $\mathrm{CD}^{+}{ }^{+} \mathrm{T}$ cells during distinct immune responses, that we herein report. Regardless, they reinforce our concept that c-Maf has context-specific effects on the immune response.

Taken together our findings demonstrate that c-Maf has a broad yet context-specific role in regulating gene expression allowing each type of $\mathrm{T}$ effector immune response to occur in a 
controlled yet effective manner. Our study also highlights the utility of genome-wide analyses that span multiple layers of transcriptional regulation to reveal and validate gene networks.

\section{Data Availability}

The materials, data, code and any associated protocols that support the findings of this study are available from the corresponding author upon request. The RNA-seq and ATAC-seq data sets have been deposited in the Gene Expression Omnibus database under accession number GSE106464.

\section{Materials and methods}

Animals

All mice were bred and maintained under specific pathogen-free conditions at The Francis Crick Institute, Mill Hill laboratory according to the Home Office UK Animals (Scientific Procedures) Act 1986 and used mostly at 8-12 weeks of age. C57BL/6/J wild-type mice were bred in-house. Foxp3RFP IL-10GFP were provided by RA Flavell18,47. Maf ${ }^{\mathrm{fl} / \mathrm{fl}}$ mice provided by M. Sieweke and C. Birchmeier (Max Delbrück Centre for Molecular Medicine, Germany)48, were backcrossed to C57B1/6/J mice for ten generations and subsequently crossed to $C d 4$-cre mice49 to generate $M a f^{\mathrm{fl} / \mathrm{fl}} \mathrm{Cd} 4$-cre mice, with $M a f^{\mathrm{fl} / \mathrm{fl}}$ mice used as controls. $B c l \sigma^{\mathrm{fl} / \mathrm{fl}}$ (ref. 50) were crossed to Cd4-cre to generate $B c l b^{\mathrm{fl} / \mathrm{fl}} \mathrm{Cd} 4$-cre mice. All animal experiments were carried out in accordance with UK Home Office regulations (project licenses: malaria, 80/2358; HDM allergy, 80/2506; EAE, 70/7643) and were approved by The Francis Crick Institute Ethical Review Panel.

\section{T cell sorting and in vitro $T_{H}$ cell differentiation}

Naive $\mathrm{CD} 4{ }^{+} \mathrm{CD} 62 \mathrm{~L}^{+} \mathrm{CD} 44^{10} \mathrm{CD} 25^{-} \mathrm{T}$ cells were purified from mouse spleens following negative enrichment of $\mathrm{CD} 4^{+} \mathrm{T}$ cells and sorted on a MoFlo ${ }^{\mathrm{TM}} \mathrm{XDP}$ cytometer (Beckman Coulter) using CD4 (RM4-5) e450, CD62L (MRL-14) PE-Cy7, CD44 (IM7) PE and CD25 (PC61.5) APC antibodies (all eBioscience) to over 95\% purity. Sorted T cells at $5 \times 10^{5}$ per well in flat-bottom 48-well plates were activated with plate-bound anti-CD3 $(2 \mu \mathrm{g} / \mathrm{ml}$, 145-2C11, Harlan) and anti-CD28 (10 $\mu \mathrm{g} / \mathrm{ml}, 37.51$, Harlan) and cultured in IMDM $\left(\mathrm{T}_{\mathrm{H}} 17\right)$ or with anti-CD3 $(5 \mu \mathrm{g} / \mathrm{ml})$ and soluble anti-CD28 $(2 \mu \mathrm{g} / \mathrm{ml})$ and cultured in RPMI (other cell types) and cultured under the following conditions for 7 days unless otherwise stated. $\mathrm{T}_{\mathrm{H}}$ 0+block: anti-IL-12p40 (C17.8.20, gift from G. Trinchieri, Wistar Institute, USA), antiIFN- $\gamma$ (XMG1.2, Harlan), anti-IL-4 (11.B.11, gift from DNAX), anti-IL-6 (MP5-20F3, gift from DNAX) and anti-TGF- $\beta$ (1D11.16, gift from DNAX) at $10 \mu \mathrm{g} / \mathrm{ml}$. $\mathrm{T}_{\mathrm{H}} 0$ : no cytokines or blocking antibodies were added. $\mathrm{T}_{\mathrm{H}} 1$ (+IL-27): rmIL-12p70 $(5 \mathrm{ng} / \mathrm{ml}$, Biolegend) and anti-IL-4 with or without (rmIL-27, 20ng/ml, R\&D Systems). $\mathrm{T}_{\mathrm{H}} 2: \mathrm{rmIL}-4$ (10 ng/ml; R\&D Systems), IL-2 (5 ng/ml; Insight Biotechnology), anti-IL-12p40 and anti-IFN- $\gamma$. $\mathrm{T}_{\mathrm{H}} 17$ : rhTGF- $\beta 1$ ( $2 \mathrm{ng} / \mathrm{ml}$, R\&D Systems), rhIL-6 (50 ng/ml, R\&D Systems) and anti-IFN- $\gamma$, antiIL-4 and anti-IL-12 for 5 days. VitD3+Dex: Vitamin D3 (4x10-8 M, Enzo Life Sciences), Dexamethasone ( $1 \times 10^{-8} \mathrm{M}$, Sigma-Aldrich) anti-IL-4, anti-IFN- $\gamma$, anti-IL-12 for 21 days. 
$\mathrm{T}_{\text {reg }}$ cells: $\mathrm{CD}^{+}$(CD4 APCe780, eBioscience) Foxp3RFP ${ }^{+}$IL-10GFP- $^{-}$or Foxp3RFP ${ }^{+}$IL-10GFP ${ }^{+}$were sorted directly ex vivo.

For RNA, cells were either taken at the end of the culture ( 0 hour), or restimulated with antiCD3 and anti-CD28 at $2 \mu \mathrm{g} / \mathrm{ml}$ each for 0.5, 2 and 6 hours. Two (Naive, $\mathrm{T}_{\mathrm{H}} 0, \mathrm{~T}_{\mathrm{H}} 0+\mathrm{block}$, $\mathrm{T}_{\mathrm{H}} 1, \mathrm{~T}_{\mathrm{H}} 1+\mathrm{IL}-27, \mathrm{~T}_{\mathrm{H}} 2, \mathrm{~T}_{\mathrm{H}} 17$, VitD3+Dex; for each biological replicate, RNA was pooled from technical triplicates unless otherwise stated) or three (IL-10 ${ }^{+}$vs IL-10- $\mathrm{T}_{\text {reg }}$ cells) independent biological experiments were performed. To assess the effect of c-Maf on CD4 ${ }^{+}$ $\mathrm{T}$ cells differentiation in vitro, naive $M a f^{f l / f l} C d 4$ cre vs $M a f^{f l / f l} \mathrm{CD} 4^{+} \mathrm{T}$ cells were sorted and stimulated with anti-CD3 and anti-CD28 $(5 / 2 \mu \mathrm{g} / \mathrm{ml}$ respectively - medium alone, $5 \mathrm{ng} / \mathrm{ml}$ IL-12, 25ng/ml IL-27, IL-12+IL-27, $10 \mathrm{ng} / \mathrm{ml} \mathrm{IL-4,} 50 \mathrm{ng} / \mathrm{ml}$ IL-21 or IL-4+IL21 in RPMI; $2 / 10 \mu \mathrm{g} / \mathrm{ml}$ respectively $-0.5 \mathrm{ng} / \mathrm{ml}$ TGF- $\beta$ alone or with $2 \mathrm{ng} / \mathrm{ml}$ TGF- $\beta$ and $50 \mathrm{ng} / \mathrm{ml}$ IL-6 plus or minus $10 \mu \mathrm{g} / \mathrm{ml}$ anti-IL-2 (JES6-1A12, Bio X Cell) in IMDM) for up to 5 days.

\section{Disease models}

Malaria: Mice (male) housed under reverse light were infected intraperitoneally with $10^{5}$ Plasmodim chabaudi chabaudi AS infected red blood cells (RBC). Blood smears were taken daily (am) when parasite sequestration is low in order to best estimate the level of parasitemia, the proportion of parasitized RBCs were monitored as described previously51. Measurements of clinical pathology, body weight and temperature (measured using a noninvasive thermometer, Fluke), were also taken daily (pm) and calculated relative to the day 0 baseline. For RNA-seq and ATAC-seq, T cells were enriched by negative selection from individual spleens ( 3 mice each $M a f^{f l / f l}$ and $M a f^{f l / f l} C d 4$ cre) on day 7 post infection as described above and Ter119-CD3 ${ }^{+} \mathrm{CD} 4{ }^{+} \mathrm{T}$ cells (Ter119 (TER-119) APCCy7, BD; CD3 (145-2C11) APC, CD4 (RM4-5) e450, eBioscience) were sorted on MoFlo ${ }^{\mathrm{TM}}$ XDP or BD Fusion cytometer.

\section{House dust mite (HDM)-induced airway allergy}

Mice (female) were sensitized with $10 \mathrm{mg}$ HDM (Greer) or PBS and 2mg Imject Alum (Thermo Scientific) by intraperitoneal injections on days 0 and 14, and challenged intratracheally with $10 \mathrm{mg}$ HDM or PBS on days 21 and 24 as described previously29. On day 25 , bronchoalveolar lavage was preformed and differential cell counts obtained following Cytospin and staining with Accustain Wright-Giemsa (Sigma-Aldrich). For histology, left lung lobes were fixed in $4 \%$ formaldehyde followed by $70 \%$ ethanol and stained with hematoxylin and eosin (inflammation) and Alcian blue/periodic acid-Schiff (mucus). Sections were scored for inflammation and mucus on a 0-4 scale as described29, except the average score of all individual airways was calculated. For RNA-seq and ATACseq, $\mathrm{CD} 4^{+} \mathrm{T}$ cells were enriched by positive selection (Miltenyi Biotech) from perfused lungs on day 25 (pooled from at least $5 \mathrm{Maf} f^{\mathrm{l} / \mathrm{fl}}$ or $\mathrm{Maf} \mathrm{f}^{\mathrm{fl} / \mathrm{fl}} \mathrm{Cd} 4$-cre mice and three biological replicates were performed) following a Percoll gradient separation and $\mathrm{CD} 3{ }^{+} \mathrm{CD} 4{ }^{+} \mathrm{CD} 44^{+}$ (CD3 (145-2C11) APC, CD4 (RM4-5) e450 and CD44 (IM7) PE, eBioscience) T cells were sorted on MoFlo ${ }^{\mathrm{TM}}$ XDP cytometer. 


\section{Experimental autoimmune encephalomyelitis (EAE)}

EAE was induced by immunizing mice (male or female) subcutaneously with $250 \mu \mathrm{g}$ $\mathrm{MOG}_{35-55}$ peptide (Cambridge Research Biochemicals) emulsified in complete Freund's adjuvant containing $250 \mu \mathrm{g}$ heat-killed $M$. tuberculosis H37RA (Difco Laboratories) on day 0 . On days 0 and 2 post immunization, mice received 200ng pertussis toxin (Calbiochem) intraperitoneally. Measurements of clinical pathology (body weight and clinical score) were taken daily and calculated relative to the day 0 baseline. Disease severity scoring: no paralysis, 0; flaccid tail, 1; impaired righting reflex and/or gait, 2; partial hind limb paralysis, 3; complete hind limb paralysis, 4. For RNA-seq and ATAC-seq, CNS cells were enriched by Percoll gradient from perfused brains and spinal cords (pooled from at least $10 \mathrm{Maf} \mathrm{fl}^{\mathrm{fl} / \mathrm{fl}}$ or $M a f^{\mathrm{fl} / \mathrm{fl}} \mathrm{Cd} 4$-cre mice and three biological replicates were performed) on day 14-16 post immunization and CD45.2 ${ }^{+} \mathrm{CD}^{+} \mathrm{CD}^{+}(\mathrm{CD} 45.2$ (104) APC, CD4 (RM4-5) e450, CD4 (RM4-5) PE) T cells were sorted on MoFlo ${ }^{\mathrm{TM}} \mathrm{XDP}$ cytometer. For RNA-seq $\left(\mathrm{Maf}^{\mathrm{fl} / \mathrm{fl}}\right)$ and ATAC-seq $(\mathrm{C} 57 \mathrm{BL} / 6)$ on untreated $\mathrm{CD} 4^{+} \mathrm{T}$ cells, $\mathrm{CD} 4^{+} \mathrm{T}$ cells were purified from mouse spleens following negative enrichment and $\mathrm{CD}^{+}{ }^{+} \mathrm{CD} 4{ }^{+} \mathrm{T}$ cells (CD3 (145-2C11) APC, CD4 (RM4-5) e450) were sorted on MoFlo ${ }^{\mathrm{TM}}$ XDP cytometer.

\section{Flow cytometry and intracellular cytokine and transcription factor staining of in vitro differentiated $T_{H}$ cells}

After differentiation, T cells were re-stimulated with anti-CD3 and anti-CD28 at $2 \mu \mathrm{g} / \mathrm{ml}$ each or PDBU (Sigma-Aldrich) and Ionomycin (Calbiochem) at $500 \mathrm{ng} / \mathrm{ml}$ each $\left(\mathrm{T}_{\mathrm{H}} 17\right)$ for 4 hours, with Brefeldin A (10 $\mu \mathrm{g} / \mathrm{ml}$, Sigma-Aldrich) added for the last 2 and 4 hours of culture, respectively. Surface markers were stained in PBS together with LIVE/DEAD Fixable Blue Dead Cell Stain Kit (Molecular Probes). For intracellular cytokine detection, cells were fixed with $2 \%$ formaldehyde, permeabilized with permeabilization buffer (eBioscience) and stained with: anti-IL-2 (JES-5H4) APC-Cy7 (BD), anti-IFN- $\gamma$ (XMG1.2) PE-Cy7 (BD) and anti-IL-4 (11B11) PE, anti-IL-10 (JES5-16E3) APC, anti-IL17A (eBi17B7) FITC (eBioscience). For Foxp3 and c-Maf staining, cells were fixed with Fixation/Permeabilization buffers and stained with Foxp3 (FJK-16S) PE or c-Maf PerCPeFluor (symOF1) 710 with IgG2bK isotype (BMG2b) eFluor 710 control (eBioscience).

\section{Intracellular cytokine staining of ex vivo cells}

Malaria: spleen cells were isolated on day 12 post infection and restimulated with $50 \mathrm{ng} / \mathrm{ml}$ PMA and $500 \mathrm{ng} / \mathrm{ml}$ Ionomycin (Sigma-Aldrich) for 4 hours, with Golgi Plug (BD) added for the last 2 hours of culture. Cells were then pretreated with anti-CD16/32 (2.4G2) (BD) and surface stained in PBS with CD4 (RM4-5) BV605, CD8 (53-6.7) BV650, CD3 (145-2C11) APC-Cy7 and Zombie Aqua (Biolegend). After surface staining, cells were fixed with Fixation buffer followed by permeabilization in Perm Buffer (Biolegend) and stained intracellularly with IL-10 (JES5-16E3) FITC and IFN- $\gamma$ (XMG1.2) PE-Cy7 (eBioscience). $\mathrm{T}_{\mathrm{FH}}$ cell staining was carried out as previously described36. HDM: lung cells were isolated from the right lower lobe on day 25 using Percoll and restimulated with 50 $\mathrm{ng} / \mathrm{ml}$ PMA and $1 \mathrm{mg} / \mathrm{ml}$ Ionomycin (Sigma-Aldrich) and Golgi Stop and Plug (BD) for 6 hours. Cell were then surface stained in PBS with CD3 (17A2) e780, CD4 (RM4-5) e450, CD44 (1M7) PerCpCy5.5 (eBioscience) in the presence of anti-CD16/32 (2.4G2) together 
with LIVE/DEAD Fixable Blue Dead Cell Stain Kit (Molecular Probes). After surface staining, cells were fixed with $2 \%$ formaldehyde, permeabilized with permeabilization buffer and stained intracellularly with IL-4 (11B11) PE-Cy7 and IL-10 (JES5-16E3) APC (eBioscience). EAE: cells were isolated from spinal cords and brains on day 16 post immunization using Percoll and restimulated with 50ng/ml PMA and $500 \mathrm{ng} / \mathrm{ml}$ Ionomycin for 4 hours, with Brefeldin A (10 $\mu \mathrm{g} / \mathrm{ml}$, Sigma-Aldrich) added for the last 3 hours of culture. Cells were then pretreated with anti-CD16/32 (10 $\mu \mathrm{g} / \mathrm{ml}$, Harlan) and surface stained in PBS with CD45.2 (104) PE (eBioscience), CD3 (17A2) BV785 and CD4 (RM4-5) BV605 (Biolegend) together with LIVE/DEAD Fixable Blue Dead Cell Stain Kit (Molecular Probes). After surface staining, cells were fixed with intranuclear Fixation/ Permeabilization buffers (eBioscience) and stained with IL-17A (eBi17B7) FITC, Foxp3 (FJK-16S) PE (eBioscience) and IFN- $\gamma$ (XMG1.2) PE-Cy7 (BD). Samples were acquired on LSR II or Fortessa (BD) and analyzed using Flow Jo software (Treestar).

\section{RNA extraction and pre-processing for RNA-seq}

RNA from in vitro and ex vivo $\mathrm{CD}^{+} \mathrm{T}$ cells was extracted using RNeasy Mini Kit according to the manufacturer's instructions (Qiagen). RNA-seq libraries were made with TruSeq RNA Sample Preparation Kit V2 according to the manufacturer's instructions (for EAE, SMARTer® Ultra ${ }^{\mathrm{TM}}$ Low Input RNA Kit - v3 was used to generate cDNA which were fragmented on Covaris at 200bp before generating libraries using NuGen Ovation ultralow kit) and sequenced using the HiSeq 2500 System with single-end read lengths of 50bp, depth 27-65M reads per sample (Illumina). Alignment of reads to the mouse transcriptome (mm10) and absolute quantification of the genes was performed in Strand NGS (version 2.0) with default parameters (95\% identity, max 5\% gaps, 1 read only if duplicated, ignoring reads with more than 5 matches), guided by RefSeq annotations (2013.04.01) (in vitro $\mathrm{T}_{\mathrm{H}}$ cells and ex vivo $\mathrm{T}_{\text {reg }}$ ) or Ensembl (2014.04.01) (ex vivo CD4 ${ }^{+} \mathrm{T}$ cells from malaria, HDM allergy and EAE). See Supplementary Data for further data processing.

\section{Quantitative RT-PCR}

RNA was extracted using RNAeasy microkit (Qiagen) and reverse transcribed into cDNA using as High Capacity Reverse Transcription kit (Applied Biosystems) according to manufacturer's instructions, followed by RNaseH (Promega) treatment for $30 \mathrm{~min}$ at $37^{\circ} \mathrm{C}$. cDNA was analyzed for the expression of the following factors on the 7900HT ABI or QS3 real-time PCR systems (Applied Biosystems) using TaqMan primer probes to mouse Maf, Mm 02581355_s1; I110, Mm00439616_m1; Tbx21, Mm00450960_m1; Ifng, Mm01168134_m1; Gata3, Mm00484683_m1; Il4, Mm00445260_m1; Rorc, Mm01261019_g1 and II17a, Mm00439619_m1, Foxp3, Mm 00475162_m1, II2, Mm 00434256_m1 and II2ra, Mm 01340213_m1 all from Applied Biosystems. The comparative threshold cycle method with Hrpt1, Mm03024075_m1 as an internal control was used for the normalization of target gene expression.

\section{ATAC-seq}

Samples were prepared as described previously52, with the transposition reaction carried out for $1 \mathrm{~h}$ and 30 minutes at $37^{\circ} \mathrm{C}$ and subsequent PCR amplification for 12 cycles. For EAE, 
25,000 cells were used and the transposition reaction was scaled down accordingly, in a 25 $\mu \mathrm{l}$ reaction volume. See Supplementary Data for further data processing.

\section{Statistical Analysis}

GraphPad Prism Version 6 was used to perform experimental statistical analysis. The statistical significance of differences between data groups was determined by an unpaired, two-tailed Student's $t$-test or two-tailed Mann-Whitney test where applicable at the 95\% confidence level. For linear regression, correlation coefficients of determination and $P$ values were calculated using the mean value of biological replicates. All sequencing data analyses were performed with the R statistical package version 3.3.1 (2016) and Bioconductor libraries version 3.353 unless otherwise stated (see Supplementary Data for more information). For exact $\mathrm{n}$ values and error bars used refer to individual figure legends.

\section{Data Availability}

The materials, data, code and any associated protocols that support the findings of this study are available from the corresponding author upon request. The RNA-seq and ATAC-seq data sets have been deposited in the Gene Expression Omnibus database under accession number GSE106464.

\section{Supplementary Material}

Refer to Web version on PubMed Central for supplementary material.

\section{Acknowledgments}

We thank The Francis Crick Institute, Biological Services for breeding and maintenance of the mice; the Advanced Sequencing Platform and A. Sesay for help with sequence sample processing; the Flow Cytometry Platform; Bioinformatics Platform, G. Kelly; and Photographics, M. Butt; for assistance. We thank V. Stavropoulos for help with in vivo experiments. We thank A. Singhania and L. Moreira-Teixeira from the AOG laboratory at the Francis Crick Institute for careful review and discussion of the manuscript. AOG, LG, KP, MA, LSC, CW and work of this work of AOG was supported by the Francis Crick Institute (Crick Core), which receives its core funding from Cancer Research UK (FC001126, FC010110), the UK Medical Research Council (FC001126, FC010110), and the Wellcome Trust (FC001126, FC010110) since 1st April 2015 and before that by the UK Medical Research Council (MRC U117565642) and also by the European Research Council grant 294682-TB-PATH (Crick 10127). L.G. was additionally funded by an MRC Centenary Award. JL was funded by the Crick Core project code 10101; JB and VM were funded by the Crick Core project FC001051 and by the Wellcome Trust WT098326MA. N.M.L. is a Winton Group Leader in recognition of the Winton Charitable Foundation's support towards the establishment of The Francis Crick Institute. N.L. is additionally funded by a Wellcome Trust Joint Investigator Award (103760/Z/14/Z), and the MRC eMedLab Medical Bioinformatics Infrastructure Award (MR/L016311/1). M.H.S is a Berlin Institute of Health-Einstein visiting fellow and supported by Inserm, CNRS (ANR-11-BSV3-0026) (DEQ. 20110421320), ERC 695093.

\section{References}

1. Sher A, Coffman RL. Regulation of immunity to parasites by T cells and T cell-derived cytokines. Annu Rev Immunol. 1992; 10:385-409. DOI: 10.1146/annurev.iy.10.040192.002125 [PubMed: 1590992]

2. Littman DR, Rudensky AY. Th17 and regulatory T cells in mediating and restraining inflammation. Cell. 2010; 140:845-858. S0092-8674(10)00174-1 [pii]. DOI: 10.1016/j.cell.2010.02.021 [PubMed: 20303875] 
3. Zhu J, Yamane H, Paul WE. Differentiation of effector CD4 T cell populations (*). Annu Rev Immunol. 2010; 28:445-489. DOI: 10.1146/annurev-immunol-030409-101212 [PubMed: 20192806]

4. Gabrysova L, Howes A, Saraiva M, O'Garra A. The regulation of IL-10 expression. Curr Top Microbiol Immunol. 2014; 380:157-190. DOI: 10.1007/978-3-662-43492-5_8 [PubMed: 25004818]

5. Josefowicz SZ, Lu LF, Rudensky AY. Regulatory T cells: mechanisms of differentiation and function. Annu Rev Immunol. 2012; 30:531-564. DOI: 10.1146/annurev.immunol. 25.022106.141623 [PubMed: 22224781]

6. Apetoh L, et al. The aryl hydrocarbon receptor interacts with c-Maf to promote the differentiation of type 1 regulatory T cells induced by IL-27. Nat Immunol. 2010; 11:854-861. DOI: 10.1038/ni.1912 [PubMed: 20676095]

7. Ciofani M, et al. A validated regulatory network for Th17 cell specification. Cell. 2012; 151:289_ 303. DOI: 10.1016/j.cell.2012.09.016 [PubMed: 23021777]

8. Cipolletta D, et al. PPAR-gamma is a major driver of the accumulation and phenotype of adipose tissue Treg cells. Nature. 2012; 486:549-553. DOI: 10.1038/nature11132 [PubMed: 22722857]

9. Jones EA, Flavell RA. Distal enhancer elements transcribe intergenic RNA in the IL-10 family gene cluster. J Immunol. 2005; 175:7437-7446. [PubMed: 16301651]

10. Li P, et al. BATF-JUN is critical for IRF4-mediated transcription in T cells. Nature. 2012; 490:543546. DOI: 10.1038/nature11530 [PubMed: 22992523]

11. $\mathrm{Li} \mathrm{W}$, et al. MiR-568 inhibits the activation and function of CD4(+) T cells and Treg cells by targeting NFAT5. Int Immunol. 2014; 26:269-281. DOI: 10.1093/intimm/dxt065 [PubMed: 24355664]

12. Mascanfroni ID, et al. Metabolic control of type 1 regulatory T cell differentiation by AHR and HIF1-alpha. Nat Med. 2015; 21:638-646. DOI: 10.1038/nm.3868 [PubMed: 26005855]

13. Motomura Y, et al. The transcription factor E4BP4 regulates the production of IL-10 and IL-13 in CD4+ T cells. Nat Immunol. 2011; 12:450-459. DOI: 10.1038/ni.2020 [PubMed: 21460847]

14. Neumann C, et al. Role of Blimp-1 in programing Th effector cells into IL-10 producers. J Exp Med. 2014; 211:1807-1819. DOI: 10.1084/jem.20131548 [PubMed: 25073792]

15. Rutz S, et al. Notch regulates IL-10 production by T helper 1 cells. Proc Natl Acad Sci U S A. 2008; 105:3497-3502. DOI: 10.1073/pnas.0712102105 [PubMed: 18292228]

16. Rutz S, et al. Transcription factor c-Maf mediates the TGF-beta-dependent suppression of IL-22 production in T(H)17 cells. Nat Immunol. 2011; doi: 10.1038/ni.2134

17. Tussiwand R, et al. Compensatory dendritic cell development mediated by BATF-IRF interactions. Nature. 2012; 490:502-507. DOI: 10.1038/nature11531 [PubMed: 22992524]

18. Wan YY, Flavell RA. Identifying Foxp3-expressing suppressor T cells with a bicistronic reporter. Proc Natl Acad Sci U S A. 2005; 102:5126-5131. DOI: 10.1073/pnas.0501701102 [PubMed: 15795373]

19. Wheaton JD, Yeh CH, Ciofani M. Cutting Edge: c-Maf Is Required for Regulatory T Cells To Adopt RORgammat(+) and Follicular Phenotypes. Journal of immunology. 2017; 199:3931-3936. DOI: $10.4049 /$ jimmunol.1701134

20. Xu M, et al. c-MAF-dependent regulatory T cells mediate immunological tolerance to a gut pathobiont. Nature. 2018; 554:373-377. DOI: 10.1038/nature25500 [PubMed: 29414937]

21. Xu J, et al. c-Maf regulates IL-10 expression during Th17 polarization. J Immunol. 2009; 182:6226-6236. DOI: 10.4049/jimmunol.0900123 [PubMed: 19414776]

22. Eychene A, Rocques N, Pouponnot C. A new MAFia in cancer. Nat Rev Cancer. 2008; 8:683-693. DOI: 10.1038/nrc2460 [PubMed: 19143053]

23. Yoshida H, Hunter CA. The immunobiology of interleukin-27. Annu Rev Immunol. 2015; 33:417443. DOI: 10.1146/annurev-immunol-032414-112134 [PubMed: 25861977]

24. Barrat FJ, et al. In vitro generation of interleukin 10-producing regulatory CD4(+) T cells is induced by immunosuppressive drugs and inhibited by T helper type 1 (Th1)- and Th2-inducing cytokines. J Exp Med. 2002; 195:603-616. [PubMed: 11877483]

25. Wang ZY, et al. Regulation of IL-10 gene expression in Th2 cells by Jun proteins. J Immunol. 2005; 174:2098-2105. [PubMed: 15699140] 
26. Freitas do Rosario AP, et al. IL-27 promotes IL-10 production by effector Th1 CD4+ T cells: a critical mechanism for protection from severe immunopathology during malaria infection. $\mathrm{J}$ Immunol. 2012; 188:1178-1190. DOI: 10.4049/jimmunol.1102755 [PubMed: 22205023]

27. Wilson MS, et al. Suppression of allergic airway inflammation by helminth-induced regulatory T cells. J Exp Med. 2005; 202:1199-1212. DOI: 10.1084/jem.20042572 [PubMed: 16275759]

28. Korn T, et al. IL-6 controls Th17 immunity in vivo by inhibiting the conversion of conventional T cells into Foxp3+ regulatory T cells. Proc Natl Acad Sci U S A. 2008; 105:18460-18465. DOI: 10.1073/pnas.0809850105 [PubMed: 19015529]

29. Coomes SM, et al. CD4 Th2 cells are directly regulated by IL-10 during allergic airway inflammation. Mucosal Immunol. 2016; doi: 10.1038/mi.2016.47

30. Bettelli E, et al. IL-10 is critical in the regulation of autoimmune encephalomyelitis as demonstrated by studies of IL-10- and IL-4-deficient and transgenic mice. J Immunol. 1998; 161:3299-3306. [PubMed: 9759845]

31. Honma S, et al. Dec1 and Dec2 are regulators of the mammalian molecular clock. Nature. 2002; 419:841-844. DOI: 10.1038/nature01123 [PubMed: 12397359]

32. Ho IC, Hodge MR, Rooney JW, Glimcher LH. The proto-oncogene c-maf is responsible for tissuespecific expression of interleukin-4. Cell. 1996; 85:973-983. [PubMed: 8674125]

33. Ho IC, Lo D, Glimcher LH. c-maf promotes T helper cell type 2 (Th2) and attenuates Th1 differentiation by both interleukin 4-dependent and -independent mechanisms. The Journal of experimental medicine. 1998; 188:1859-1866. [PubMed: 9815263]

34. Andris F, et al. The Transcription Factor c-Maf Promotes the Differentiation of Follicular Helper T Cells. Front Immunol. 2017; 8:480.doi: 10.3389/fimmu.2017.00480 [PubMed: 28496444]

35. Bauquet AT, et al. The costimulatory molecule ICOS regulates the expression of c-Maf and IL-21 in the development of follicular T helper cells and TH-17 cells. Nat Immunol. 2009; 10:167-175. ni.1690 [pii]. DOI: 10.1038/ni.1690 [PubMed: 19098919]

36. Perez-Mazliah D, et al. Follicular Helper T Cells are Essential for the Elimination of Plasmodium Infection. EBioMedicine. 2017; 24:216-230. DOI: 10.1016/j.ebiom.2017.08.030 [PubMed: 28888925]

37. Ma W, Noble WS, Bailey TL. Motif-based analysis of large nucleotide data sets using MEMEChIP. Nat Protoc. 2014; 9:1428-1450. DOI: 10.1038/nprot.2014.083 [PubMed: 24853928]

38. Chuang LS, Ito K, Ito Y. RUNX family: Regulation and diversification of roles through interacting proteins. Int J Cancer. 2013; 132:1260-1271. DOI: 10.1002/ijc.27964 [PubMed: 23180629]

39. Wang S, et al. Target analysis by integration of transcriptome and ChIP-seq data with BETA. Nat Protoc. 2013; 8:2502-2515. DOI: 10.1038/nprot.2013.150 [PubMed: 24263090]

40. Baek S, Goldstein I, Hager GL. Bivariate Genomic Footprinting Detects Changes in Transcription Factor Activity. Cell Rep. 2017; 19:1710-1722. DOI: 10.1016/j.celrep.2017.05.003 [PubMed: 28538187]

41. Djuretic IM, et al. Transcription factors T-bet and Runx3 cooperate to activate Ifng and silence Il4 in T helper type 1 cells. Nat Immunol. 2007; 8:145-153. DOI: 10.1038/ni1424 [PubMed: 17195845]

42. Kataoka K, Noda M, Nishizawa M. Maf nuclear oncoprotein recognizes sequences related to an AP-1 site and forms heterodimers with both Fos and Jun. Mol Cell Biol. 1994; 14:700-712. [PubMed: 8264639]

43. Lin CC, et al. Bhlhe40 controls cytokine production by $\mathrm{T}$ cells and is essential for pathogenicity in autoimmune neuroinflammation. Nat Commun. 2014; 5:3551.doi: 10.1038/ncomms4551 [PubMed: 24699451]

44. Muller MR, Rao A. NFAT, immunity and cancer: a transcription factor comes of age. Nat Rev Immunol. 2010; 10:645-656. DOI: 10.1038/nri2818 [PubMed: 20725108]

45. Webster KE, et al. In vivo expansion of T reg cells with IL-2-mAb complexes: induction of resistance to EAE and long-term acceptance of islet allografts without immunosuppression. The Journal of experimental medicine. 2009; 206:751-760. DOI: 10.1084/jem.20082824 [PubMed: 19332874]

46. Laurence A, et al. Interleukin-2 signaling via STAT5 constrains T helper 17 cell generation. Immunity. 2007; 26:371-381. DOI: 10.1016/j.immuni.2007.02.009 [PubMed: 17363300] 
47. Kamanaka M, et al. Expression of interleukin-10 in intestinal lymphocytes detected by an interleukin-10 reporter knockin tiger mouse. Immunity. 2006; 25:941-952. S1074-7613(06)00511-5 [pii]. DOI: 10.1016/j.immuni.2006.09.013 [PubMed: 17137799]

48. Wende H, et al. The transcription factor c-Maf controls touch receptor development and function. Science. 2012; 335:1373-1376. DOI: 10.1126/science.1214314 [PubMed: 22345400]

49. Lee PP, et al. A critical role for Dnmt1 and DNA methylation in T cell development, function, and survival. Immunity. 2001; 15:763-774. [PubMed: 11728338]

50. Kaji T, et al. Distinct cellular pathways select germline-encoded and somatically mutated antibodies into immunological memory. J Exp Med. 2012; 209:2079-2097. DOI: 10.1084/jem. 20120127 [PubMed: 23027924]

51. Freitas do Rosario AP, et al. Gradual decline in malaria-specific memory T cell responses leads to failure to maintain long-term protective immunity to Plasmodium chabaudi AS despite persistence of B cell memory and circulating antibody. J Immunol. 2008; 181:8344-8355. [PubMed: 19050251]

52. Buenrostro JD, Giresi PG, Zaba LC, Chang HY, Greenleaf WJ. Transposition of native chromatin for fast and sensitive epigenomic profiling of open chromatin, DNA-binding proteins and nucleosome position. Nat Methods. 2013; 10:1213-1218. DOI: 10.1038/nmeth.2688 [PubMed: 24097267]

53. R: A Language and Environment for Statistical Computing. 2013. 
a
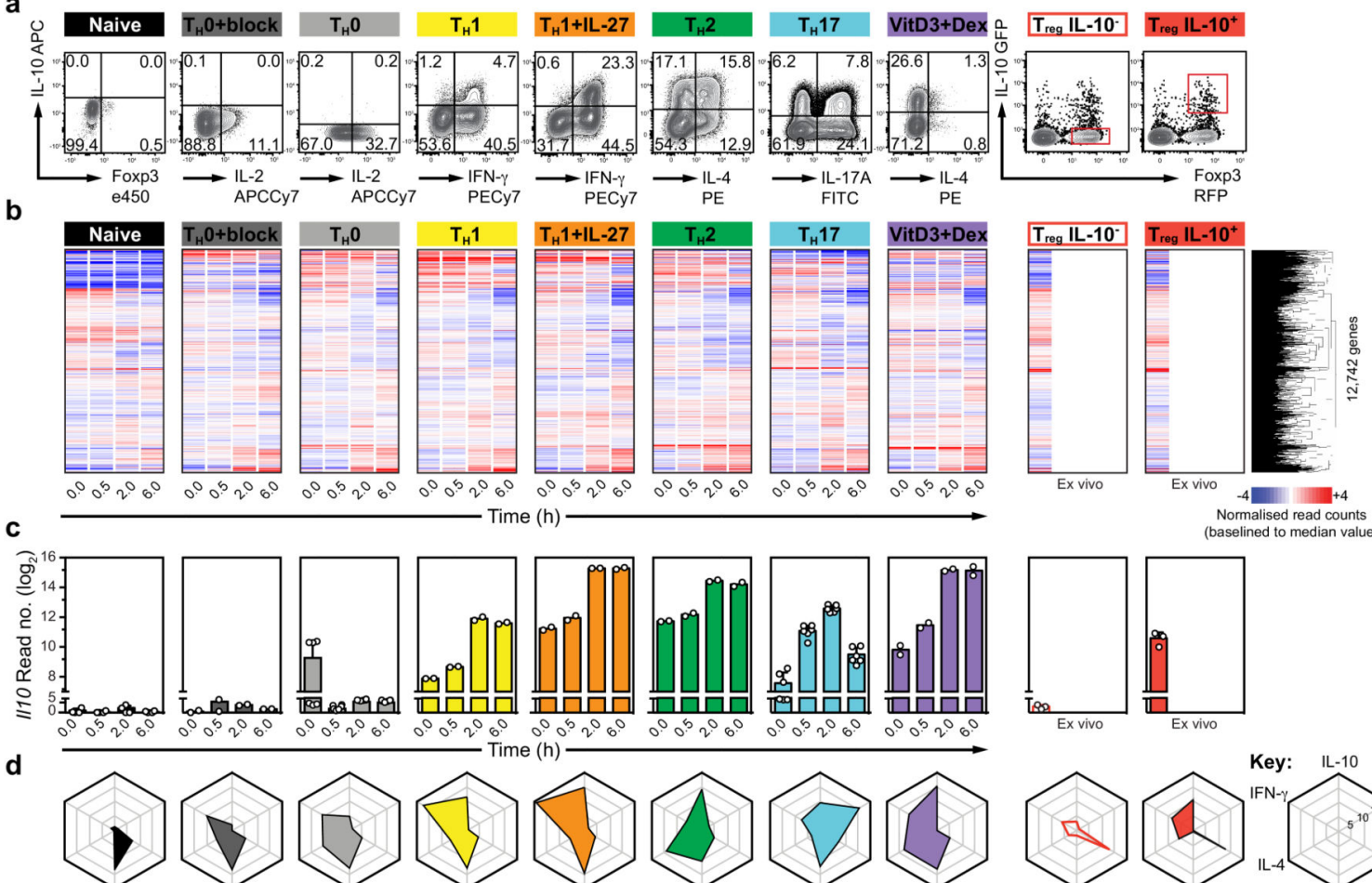

e Candidate transctiption factors ranked from left to right in the order of correlation with IL-10
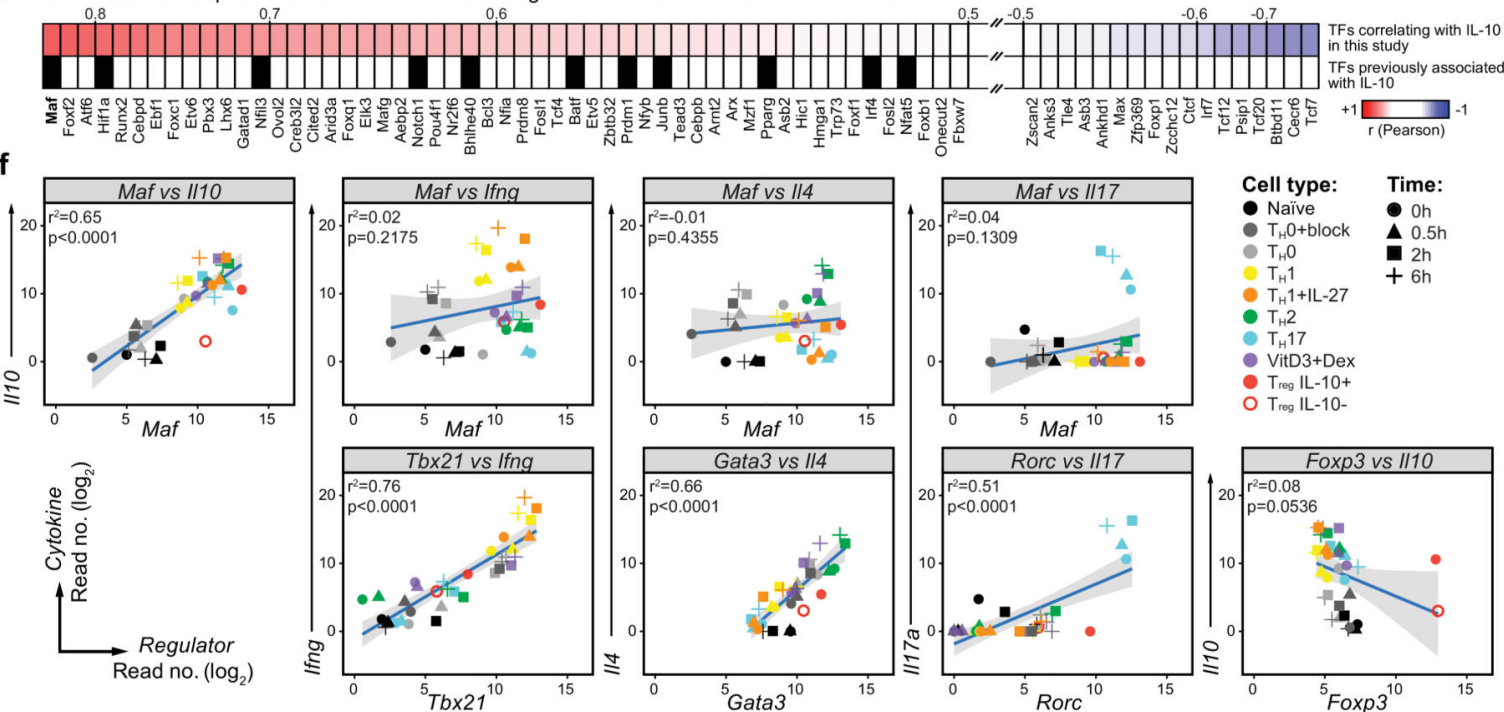

Cell type: Time:

- Naïve Oh $T_{H+1}$

$T_{H} 1$

- $T_{H} 1+$ IL-27

- $T_{H} 2$

- VitD3+Dex

Trog IL-10+

O Treg IL-10-
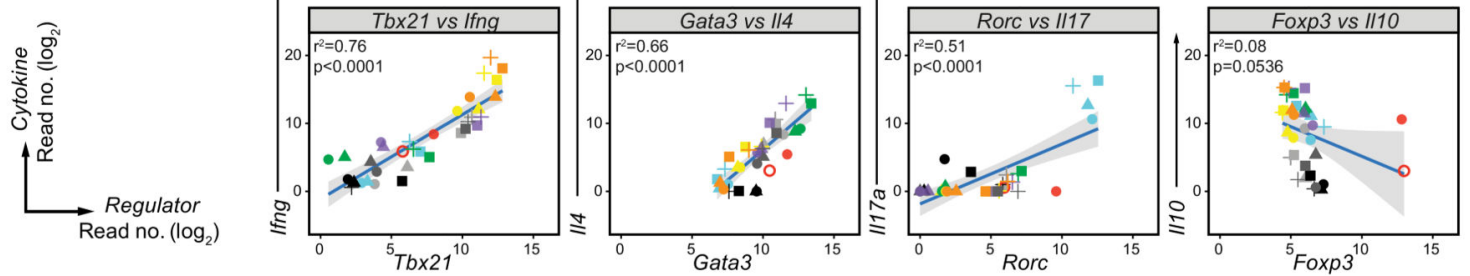

Figure 1. The transcription factor Maf correlates with $I l 10$ expression in all $\mathbf{T}_{\mathbf{H}}$ and $\mathbf{T}_{\text {reg }}$ cell subsets.

a, Representative cytokine staining of naive $\mathrm{CD}^{+} \mathrm{T}$ cells, in vitro differentiated $\mathrm{T}_{\mathrm{H}} 0$,

$\mathrm{T}_{\mathrm{H}}$ 0+block, $\mathrm{T}_{\mathrm{H}} 1, \mathrm{~T}_{\mathrm{H}} 1+\mathrm{IL}-27, \mathrm{~T}_{\mathrm{H}} 2, \mathrm{~T}_{\mathrm{H}} 17$, VitD3+Dex CD4 ${ }^{+} \mathrm{T}$ cell subsets $(\mathrm{n}=2$ independent experiments each) and of Treg cells ex vivo ( $\mathrm{n}=3$ independent experiments). $\mathbf{b}$, $\mathrm{CD}^{+}{ }^{+} \mathrm{T}$ cells from (a) were profiled by RNA-seq. Heatmap showing the mean gene expression levels $\left(12,742\right.$ genes) of naive $C D 4^{+} T$ cells $(n=2$ independent experiments, one of which with 3 culture wells), in vitro differentiated $\mathrm{T}_{\mathrm{H}} 0$ ( $\mathrm{n}=2$ independent experiments), 
$\mathrm{T}_{\mathrm{H}} 0+$ block ( $\mathrm{n}=2$ independent experiments, 3 culture wells each), $\mathrm{T}_{\mathrm{H}} 1$ ( $\mathrm{n}=2$ independent experiments), $T_{H} 1+I L-27$ ( $n=2$ independent experiments), $T_{H} 2$ ( $n=2$ independent experiments), $\mathrm{T}_{\mathrm{H}} 17$ ( $\mathrm{n}=2$ independent experiments, 3 culture wells each), VitD3+Dex ( $\mathrm{n}=2$ independent experiments) after culture ( $0 \mathrm{~h}$ ) or following a $0.5,2$ and $6 \mathrm{~h}$ re-stimulation in vitro and of $\mathrm{T}_{\text {reg }}$ cells ex vivo, either Foxp3RFP ${ }^{+} \mathrm{IL}^{-10 \mathrm{GFP}^{+}}$or IL-10GFP $(\mathrm{n}=3$ independent experiments each). c, d Expression of $I 110$ (mean \pm SD) (c) and of hallmark cytokines at $6 \mathrm{~h}$ post restimulation ( $\mathrm{d}$, values represent $\log _{2}$ of the mean expression value per population) in the different $\mathrm{CD} 4^{+} \mathrm{T}$ cell populations from (b). e, Transcription factors positively and negatively correlating with the expression of $I 110$ across all the different $\mathrm{CD} 4^{+} \mathrm{T}$ cell populations from (b) (Pearson correlation, transcription factors previously associated with IL-10 highlighted in black). f, Linear regression of $I 110$ and hallmark cytokines vs $M a f$ or $\mathrm{T}_{\mathrm{H}}$ subset master regulators (symbols represent the mean read counts per $\mathrm{CD} 4^{+} \mathrm{T}$ cell subset per timepoint from (b), shaded area $95 \% \mathrm{CI}$ ). 
a

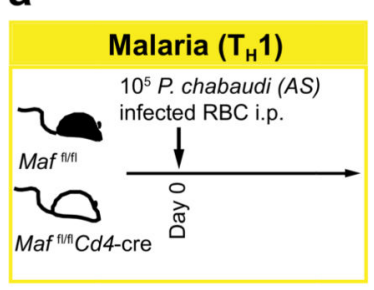

b

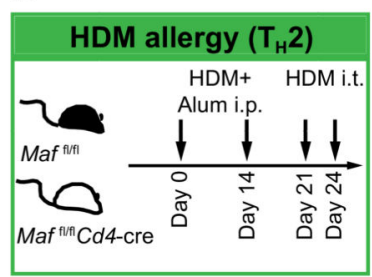

d
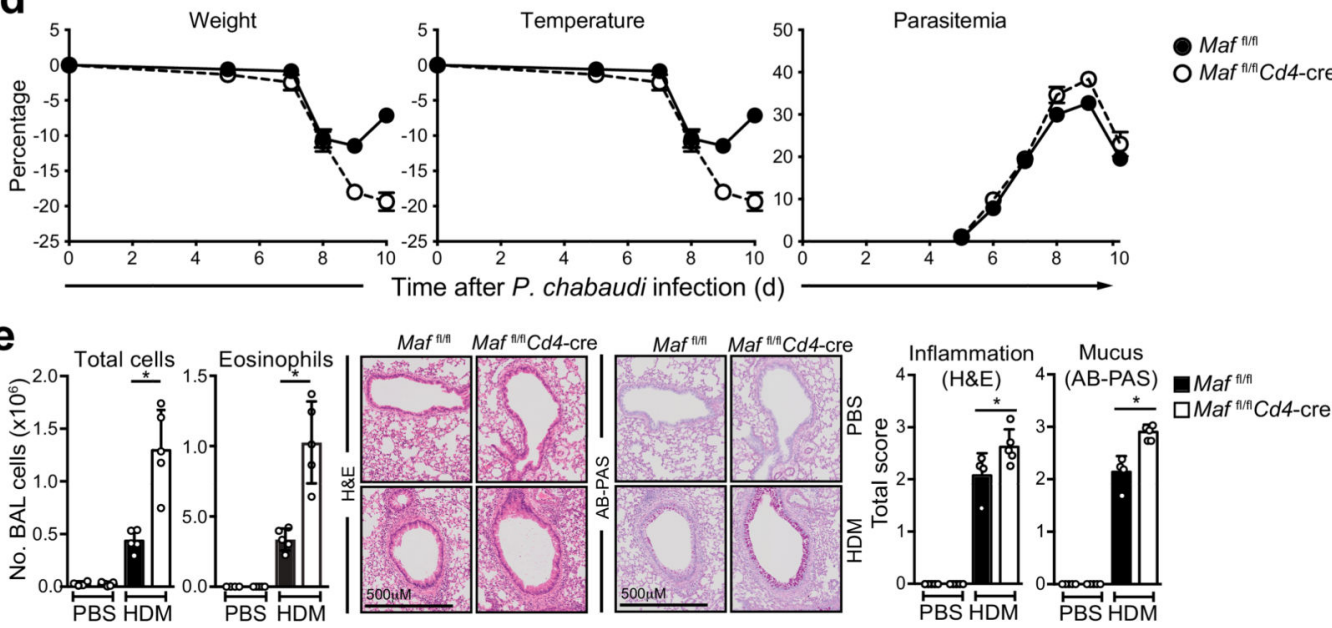

C

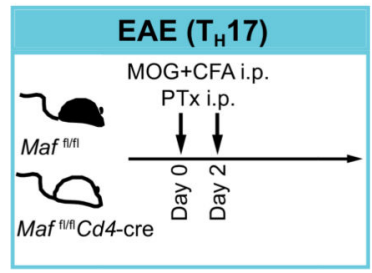

f

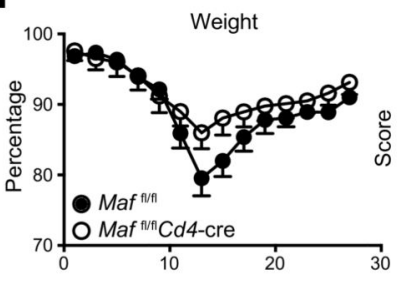

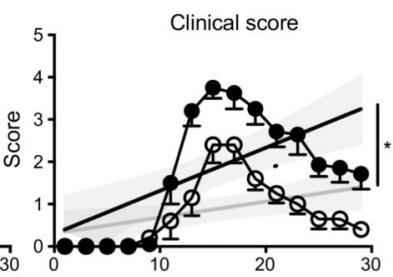

Time after immunization (d)

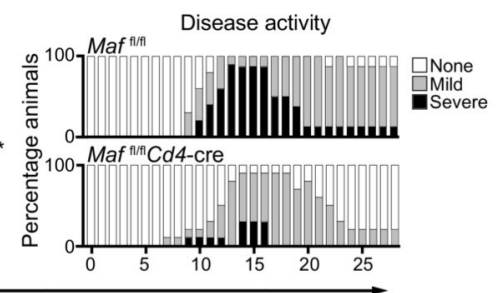

Figure 2. c-Maf deficiency in $\mathrm{CD4}^{+} \mathrm{T}$ cells affects susceptibility to disease in a context-specific manner.

a-c, Schematics of $P$. chabaudi infection, HDM allergy and EAE disease models performed in $M a f^{f l / f l}$ and $M a f^{f l / f l} C d 4$ cre mice. d, Weight loss, temperature and parasitemia during $P$. chabaudi infection ( $\mathrm{n}=14$, mean $\pm \mathrm{SEM})$. e, Total cell and differential Giemsa-stained eosinophil counts from BAL upon HDM challenge ( $n=5$, mean \pm SD), representative lung sections and cumulative total inflammation (H\&E) and mucous (AB-PAS) scores $(*, P<$ 0.05 Mann-Whitney, two-tailed). f, Weight loss and clinical score (including linear regression *, $P \leq 0.035$ F-test) during EAE (n=10, mean \pm SEM), distribution of disease severity (no EAE $=$ score $<2$, mild EAE $=$ score 2-3, severe EAE $>$ score 4, n=28).

Representative data from three biological experiments per disease model are shown. 

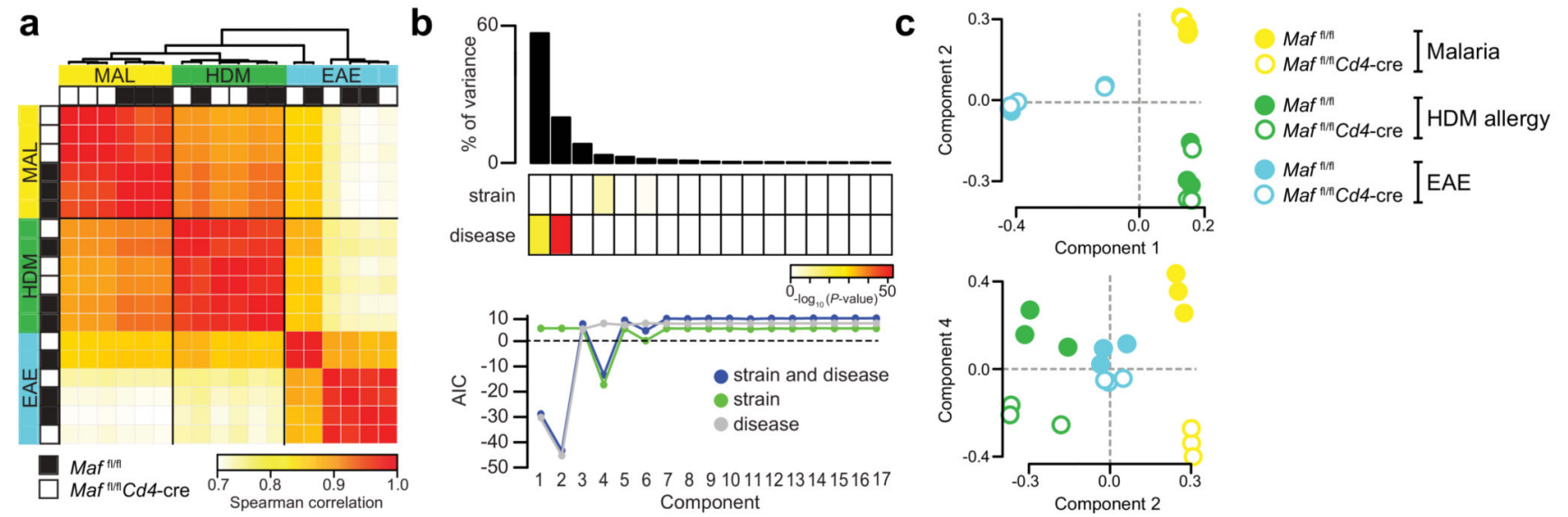

d Component 1: (58\% of variance)

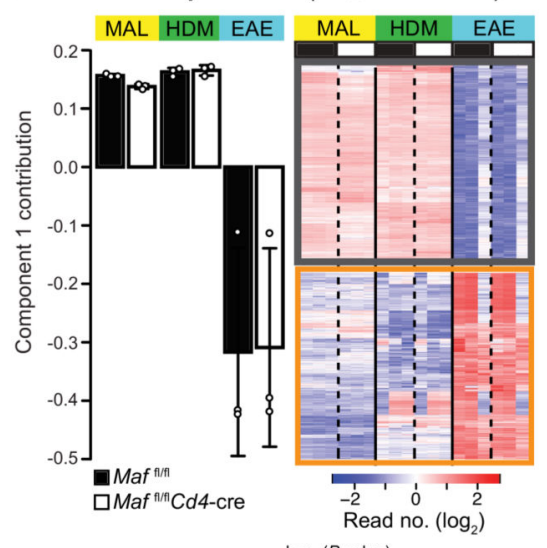

Biological pathway: $\quad \stackrel{0 . \log _{10}(P \text {-value })}{+} 8$ Example:

\begin{tabular}{|c|c|c|}
\hline $\begin{array}{l}\text { reg. transcript. Rnpll prom. } \\
\text { protein autophosphorylation } \\
\text { actin cytoskeleton organiz. } \\
\text { protein transport } \\
\text { cell cycle } \\
\text { apoptosis in morphogenesis }\end{array}$ & $\begin{array}{l}67 / 1014 \\
24 / 224 \\
44 / 536 \\
90 / 1611 \\
113 / 1438 \\
6 / 29 \\
\end{array}$ & $\begin{array}{l}\text { Sp1, Ets2 } \\
\text { Atm, Uhmk1 } \\
\text { Mtor, Emd } \\
\text { Tram2, Myh9 } \\
\text { Atm, Cdc27 } \\
\text { Notch1, Fzd5 }\end{array}$ \\
\hline $\begin{array}{l}\text { chemokine signal. pathway } \\
\text { response to radiation } \\
\text { pos. reg. of ERK1/2 } \\
\text { response to IFN- } \gamma \\
\text { inflammatory response } \\
\text { cellular response to IL-1 }\end{array}$ & $\begin{array}{l}7 / 55 \\
13 / 360 \\
12 / 166 \\
13 / 83 \\
43 / 570 \\
11 / 61\end{array}$ & $\begin{array}{l}\text { Ccl1/2/4/5/6 } \\
\text { Sgk1, Bcl2 } \\
\text { Jun, Spry2 } \\
\text { Socs1, Ifitm2 } \\
\text { II23r, Ccr6 } \\
\text { IL17a, IL1ra }\end{array}$ \\
\hline
\end{tabular}

Component 2: (20\% of variance)

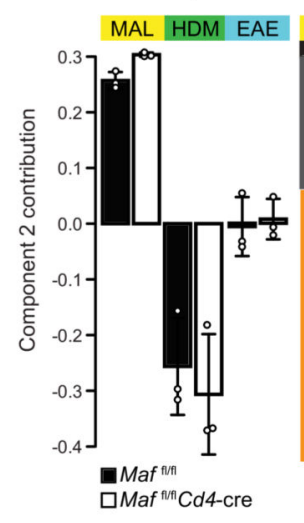

\begin{tabular}{|c|c|c|}
\hline Biological pathway: & $\stackrel{10}{0}^{-\log _{10}(P \text {-value })} 14$ & Example: \\
\hline $\begin{array}{l}\text { neutrophil chemotaxis } \\
\text { microtubule-based process } \\
\text { innate immune response } \\
T \text { cell differentiation } \\
\text { pos. reg. of cell death } \\
\text { metabolic process }\end{array}$ & $\begin{array}{l}6 / 81 \\
s 8 / 589 \\
16 / 566 \\
8 / 230 \\
9 / 592 \\
81 / 10196\end{array}$ & $\begin{array}{l}\text { Ccl3, Ccl4 } \\
\text { Tuba1c } \\
\text { Mif, Klrb1c } \\
\text { Tbx21, IFNg } \\
\text { Moap1 } \\
\text { Xdh, Atp1a2 }\end{array}$ \\
\hline
\end{tabular}

\begin{tabular}{|lll|}
\hline neg. reg. of inflammation & $9 / 100$ & Gata3, Foxp3 \\
cellular response to IL-1 & $8 / 61$ & Rora, II17a \\
pos. reg. of ERK1/2 & $15 / 166$ & Cd44, Kdr \\
angiogenesis & $30 / 424$ & Ahr, Runx1 \\
chemokine sign. pathway & $11 / 55$ & Ccl1, Ccl8 \\
inflammatory response & $51 / 570$ & $114, \| 15, \quad I 13$
\end{tabular}
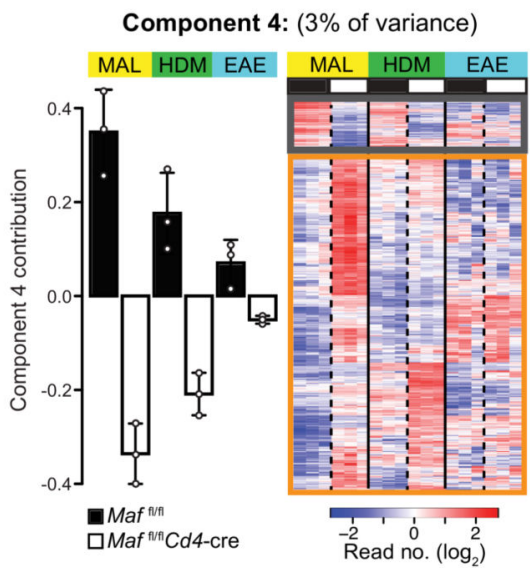

\begin{tabular}{|c|c|c|}
\hline Biological pathway: & $\begin{array}{l}-\log _{10}(P \text {-val } \\
0\end{array}$ & Example: \\
\hline $\begin{array}{l}\text { pos. reg. transcript. Rnpll prom. } \\
\text { neg. reg. of cell proliferation } \\
\text { immune response } \\
\text { pos. reg. of apoptotic process } \\
\text { neg. reg. transcritp. Rnpll prom. }\end{array}$ & $\begin{array}{l}16 / 1014 \\
13 / 609 \\
19 / 1138 \\
10 / 549 \\
9 / 731 \\
7 / 434\end{array}$ & $\begin{array}{l}\text { Maf, Arnt2 } \\
\text { Cebpa,Cdk6 } \\
\text { 1110, II21, I14 } \\
\text { Gadd45a } \\
\text { Maf, Bach2 } \\
\text { Raf1,Timp2 }\end{array}$ \\
\hline $\begin{array}{l}\text { pos. reg. of T cell proliferation } \\
\text { cellular response to TGF- } \beta \\
\text { chromatin remodeling } \\
\text { cell cycle phase transition } \\
\text { ROS metab. proc. } \\
\text { DNA replication }\end{array}$ & $\begin{array}{l}6 / 89 \\
8 / 110 \\
9 / 165 \\
13 / 313 \\
9 / 230 \\
19 / 281\end{array}$ & $\begin{array}{l}\text { IL2ra, Xcl1 } \\
\text { Runx3,Strap } \\
\text { Hdac2, Hells } \\
\text { E2f1, Tcf19 } \\
\text { Cybb, Prdx4 } \\
\text { Orc6, Chaf1b }\end{array}$ \\
\hline
\end{tabular}

Figure 3. Deciphering c-Maf driven transcriptional programmes within dominant diseaseassociated immune responses.

$\mathrm{CD}^{+} \mathrm{T}$ cells from malaria, HDM and EAE challenged $M a f^{\mathrm{fl} / \mathrm{fl}} C d 4$ cre and $\mathrm{Maf} \mathrm{f}^{\mathrm{l} / \mathrm{fl}}$ mice were profiled by RNA-seq. a, Unsupervised hierarchical clustering heatmap showing the Spearman correlation of the mean gene expression levels between the different diseases and mice. b, Singular value decomposition (SVD) was used to identify major sources of gene expression variation between malaria, HDM and EAE challenged $\mathrm{Maf}^{\mathrm{fl} / \mathrm{fl}} \mathrm{Cd} 4$-cre and $\mathrm{Maf}^{\mathrm{fl} / \mathrm{fl}}$ mice ( $\mathrm{n}=3$ independent animals (malaria) or biologically independent samples (HDM and EAE) per genotype); analyses of variance (ANOVA; shown as -log $P$-value of the chi-squared test) and the Akaike Information Criterion (AIC) were then used to test the association of each component with the disease and/or strain. c, Scatter plot showing the 
relative separation between malaria, HDM and EAE challenged $M a f^{f l / f l} C d 4$ cre and $M a f^{f l / f 1}$ mice ( $\mathrm{n}=3$ independent animals (malaria) or biologically independent samples (HDM and EAE) per genotype) along components 1, 2 and 4. d, (Upper left) Bar plots showing the average right singular vectors for components 1,2 and 4 for each condition $(n=3$ independent animals (malaria) or biologically independent samples (HDM and EAE) per genotype, mean \pm SEM); (upper right) heatmaps displaying the expression levels of the most positively (dark grey box) and negatively (light grey box) contributing and correlating genes with the right singular vectors of the corresponding component; (lower) lists of top biological pathways and example genes by GO enrichment analysis of each component ( $\mathrm{n}=3$ independent animals (malaria) or biologically independent samples (HDM and EAE) per genotype). 

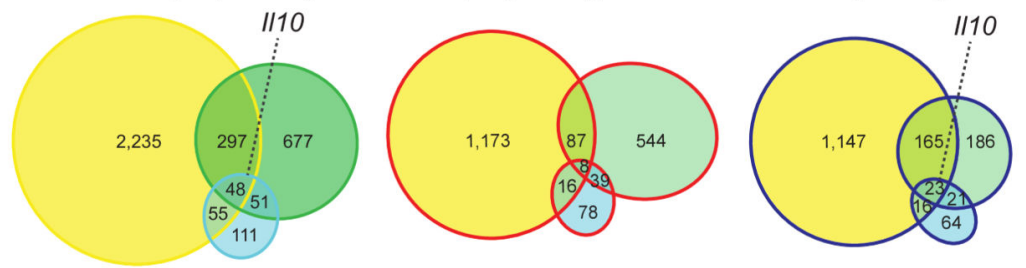

Malaria

HDM allergy

- EAE

Up-regulated genes

Down-regulated genes

b
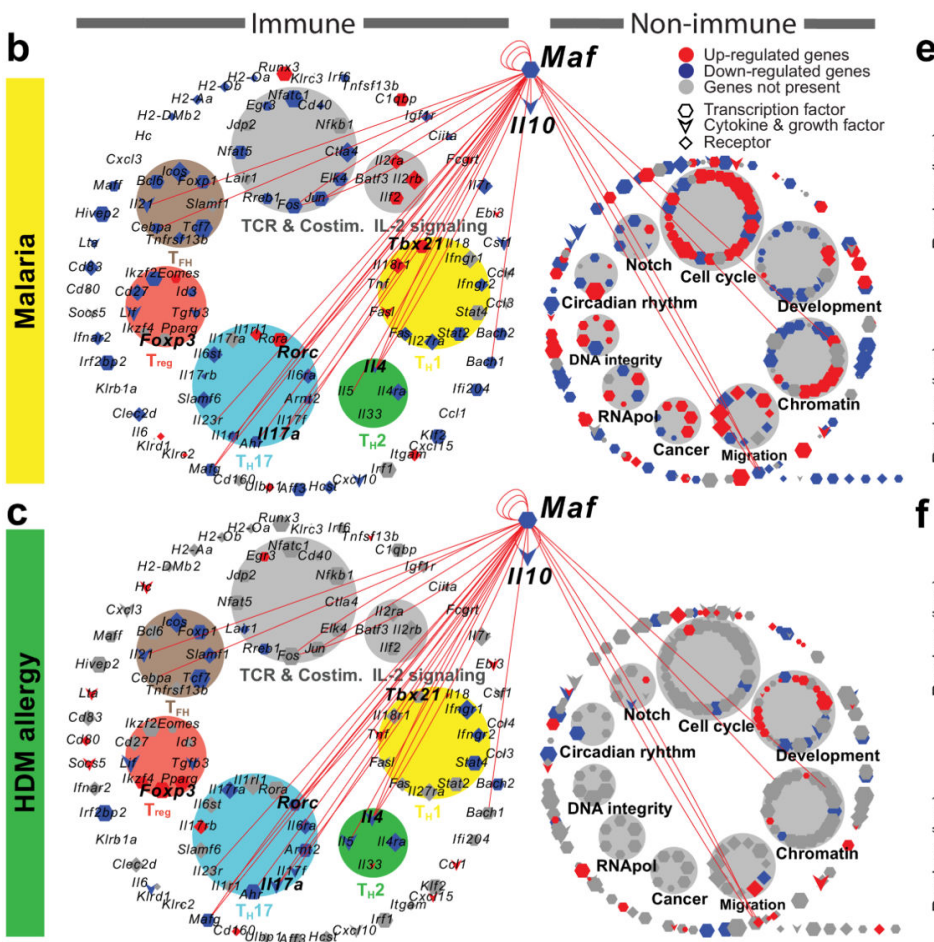

f
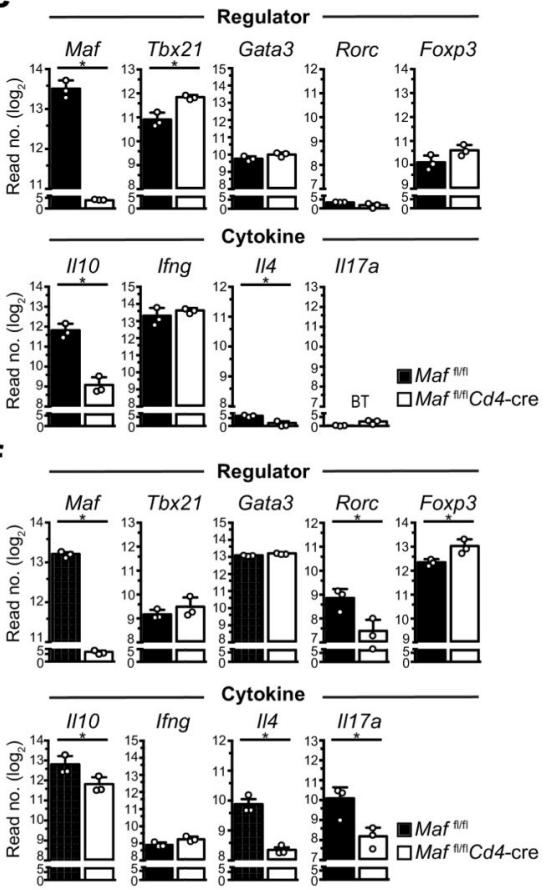

d

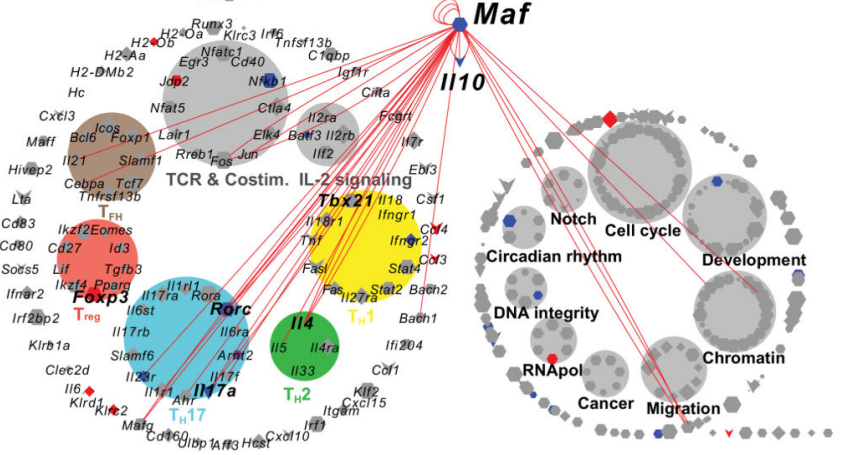

g
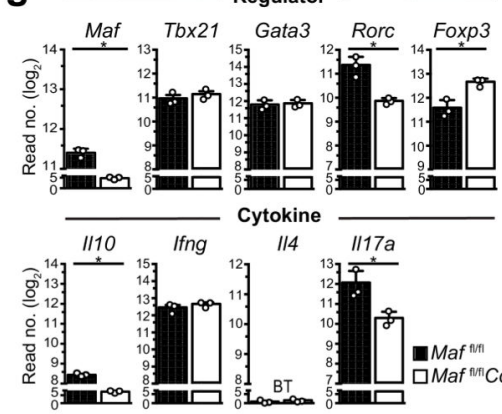

Figure 4. c-Maf regulates $\mathrm{Il10}$ expression in $\mathrm{CD4}^{+} \mathrm{T}$ cells in vivo with wider disease-specific effects.

a, Venn diagrams showing the overlap of differentially expressed, up- and down-regulated genes in $\mathrm{CD}^{+} \mathrm{T}$ cells from malaria, HDM allergy and EAE challenged $\mathrm{Maf}^{\mathrm{fl} / \mathrm{fl}} \mathrm{Cd} 4$-cre vs $\mathrm{Maf}^{\mathrm{fl} / \mathrm{fl}}$ mice ( $\mathrm{n}=3$ independent animals (malaria) or biologically independent samples (HDM and EAE) per genotype; $P<0.05$, absolute FC $\geq 1.5$, moderated $t$-test, two-tailed). bd, Networks of differentially expressed transcription factor, cytokine and trans-membrane receptor genes (blue, down-regulated; red, up-regulated; size of symbol, mean read number; 
red lines, known c-Maf interactions). e-g, Normalized read counts of selected $\mathrm{T}_{\mathrm{H}}$ cell master regulator transcription factors and hallmark cytokines in $\mathrm{CD} 4^{+} \mathrm{T}$ cells from malaria, $\mathrm{HDM}$ allergy and EAE challenged mice ( $\mathrm{n}=3$ independent animals (malaria) or biologically independent samples (HDM and EAE) per genotype, mean $\pm \mathrm{SD}$; *, $P<0.05$, absolute $\mathrm{FC} \geq$ 1.5 , moderated $t$-test, two-tailed; BT, below filtering threshold). 

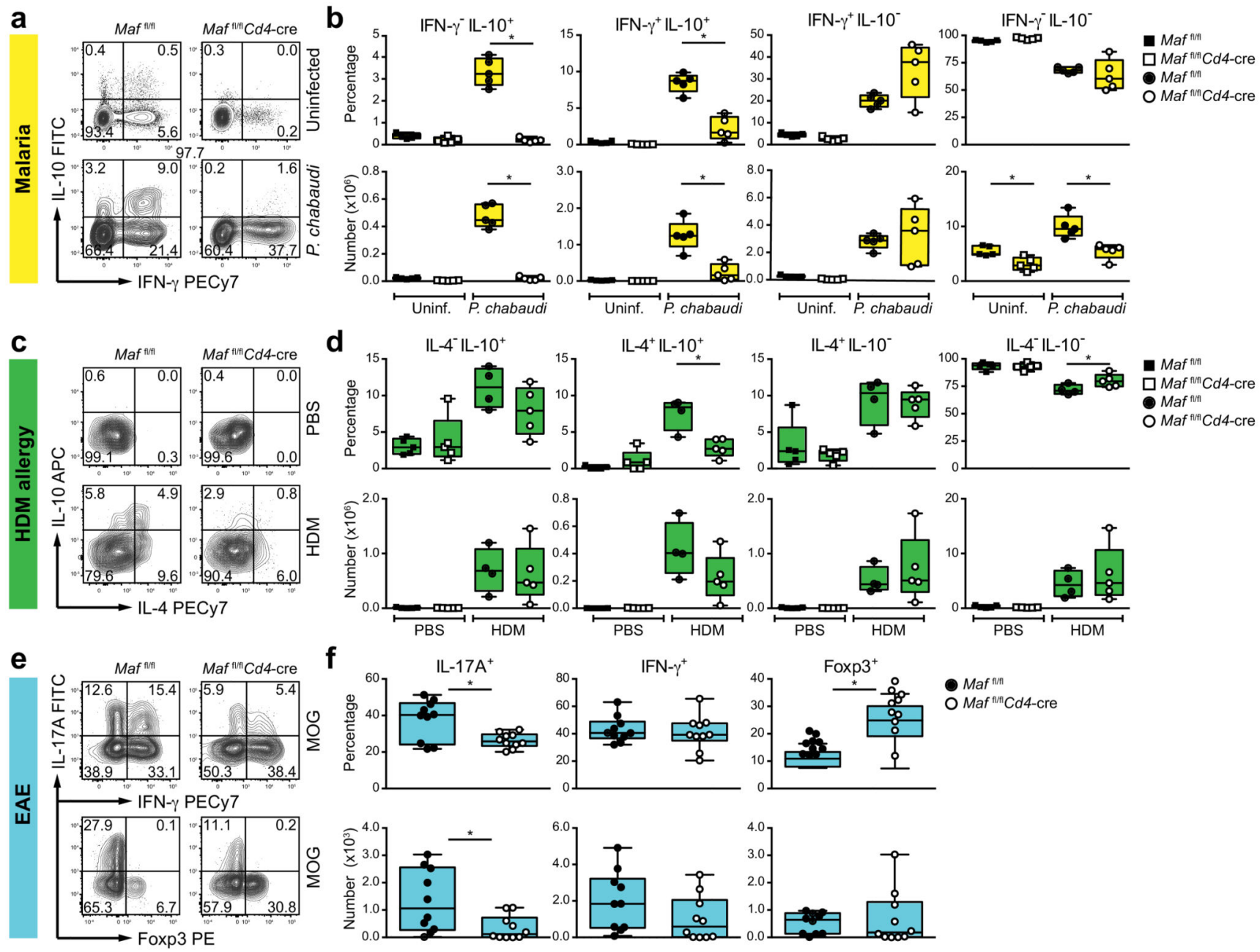

Figure 5. c-Maf deficiency results in the loss of IL-10 secreting effector $T_{H} 1$ and $T_{H} 2$ cells in malaria and HDM allergy disease models, whilst in EAE c-Maf plays a dominant role in

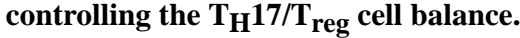

a, c, e, Representative cytokine staining of $\mathrm{CD}^{+} \mathrm{T}$ cells from malaria (speen), HDM allergy (lung) and EAE (spinal cord) challenged $\mathrm{Maf}^{\mathrm{fl} / \mathrm{fl}} \mathrm{Cd}$-cre and $\mathrm{Maf} \mathrm{fl}^{\mathrm{l} / \mathrm{fl}}$ mice gated on live $\mathrm{CD}^{+}\left(\mathrm{CD} 4^{+} \mathrm{CD} 44^{+}, \mathrm{HDM}\right) \mathrm{T}$ cells. b, d, f, Representative box plots (box limits are at the 25-75 centiles, centre line reprents the median and whiskers represent the minimum and maxium values) of percentages (top row) and numbers (bottom row) of cytokine-secreting $\mathrm{CD}^{+}{ }^{+} \mathrm{T}$ cells from malaria $(\mathrm{n}=5), \mathrm{HDM}$ allergy $(\mathrm{n}=5)$ and EAE $(\mathrm{n}=10)$ disease models $(*, P$ $<0.05$, unpaired $t$-test, two-tailed) Representative data from three biological experiments are shown. 


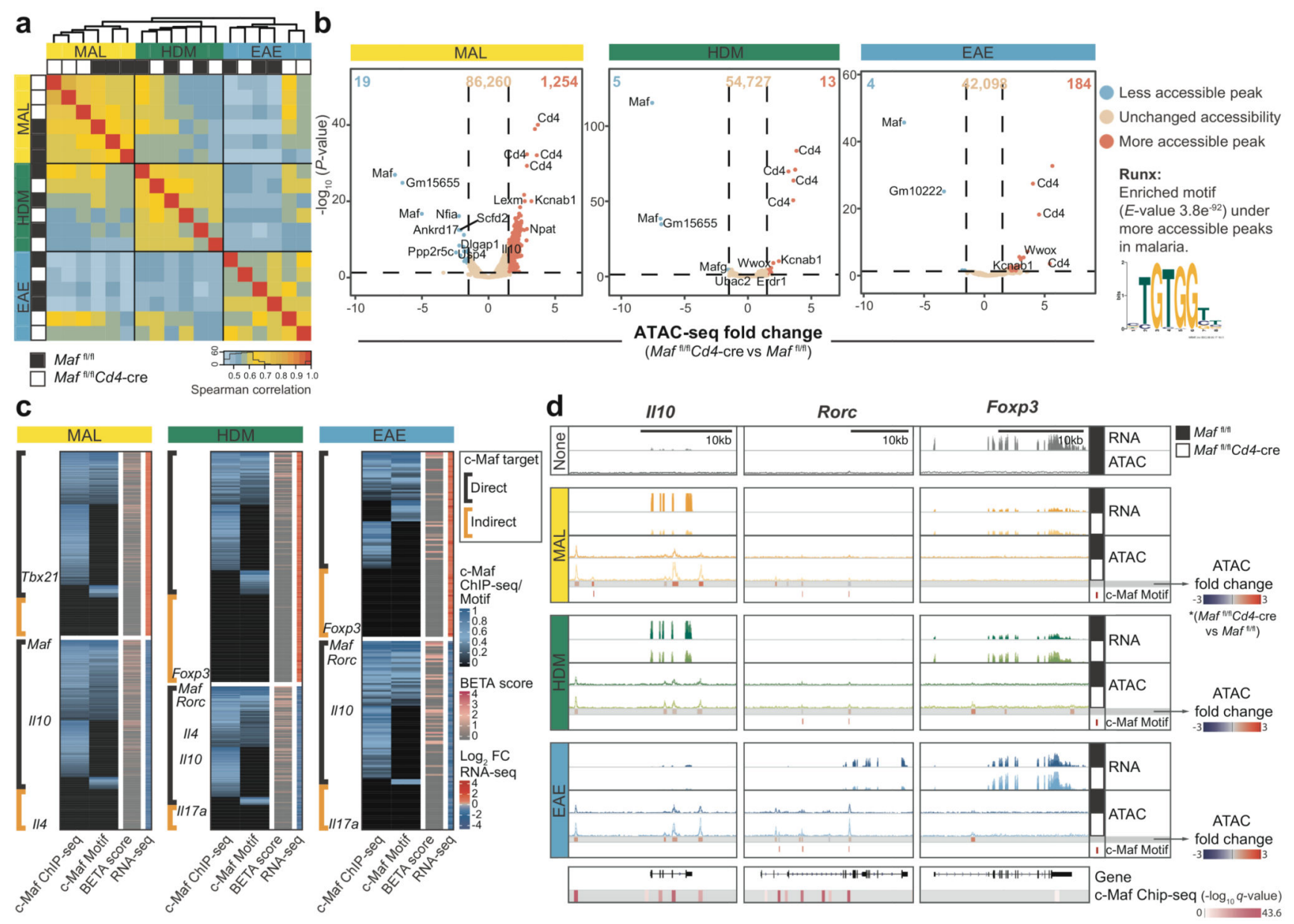

Figure 6. The context specificity of c-Maf on the immune response is driven by both direct and indirect mechanisms.

a, Heatmap showing the Spearman correlation between read coverages underlying ATACseq peaks called in $\mathrm{CD}^{+} \mathrm{T}$ cells from malaria, HDM and EAE challenged $\mathrm{Maf}^{\mathrm{fl} / \mathrm{fl}} \mathrm{Cd}$-cre and $\mathrm{Maf}^{\mathrm{fl} / \mathrm{fl}}$ mice profiled by ATAC-seq ( $\mathrm{n}=3$ independent animals (malaria) or biologically independent samples (HDM and EAE) per genotype). b, Volcano plots of changes in ATACseq consensus peak sets between $M a f^{f l / f l} C d 4$-cre and $M a f^{f l / f l}$ (statistical significance called using DiffBind 2.02 with FDR $<0.05$, absolute fold change $\geq 1.5$ ); top 10 peaks ranked by fold-change are labelled with the assigned target gene, as well as those peaks assigned to I110. De novo motif discovery identified the Runx TF family motif as the top match in differentially accessible ATAC-seq peaks in the malaria model (MEME-ChIP, E-value 3.8e-92). c, Heatmaps for differentially expressed genes indicating the presence of ATACseq peaks with overlapping c-Maf ChIP-seq occupancy and/or c-Maf motif matches (called direct targets, black bracket), or neither (indirect targets, orange bracket). Putative direct and indirect targets are further corroborated using the BETA software with high scores representing greater likelihood of direct regulation. d, Genome browser tracks of read coverage of RNA-seq and ATAC-seq in $\mathrm{CD}^{+}{ }^{+} \mathrm{T}$ cells from the different disease models (shown as an overlay of $n=3$ independent animals (malaria) or biologically independent 
samples (HDM and EAE) per genotype) as compared to untreated control and matched to cMaf ChIP-seq and motif sites. 

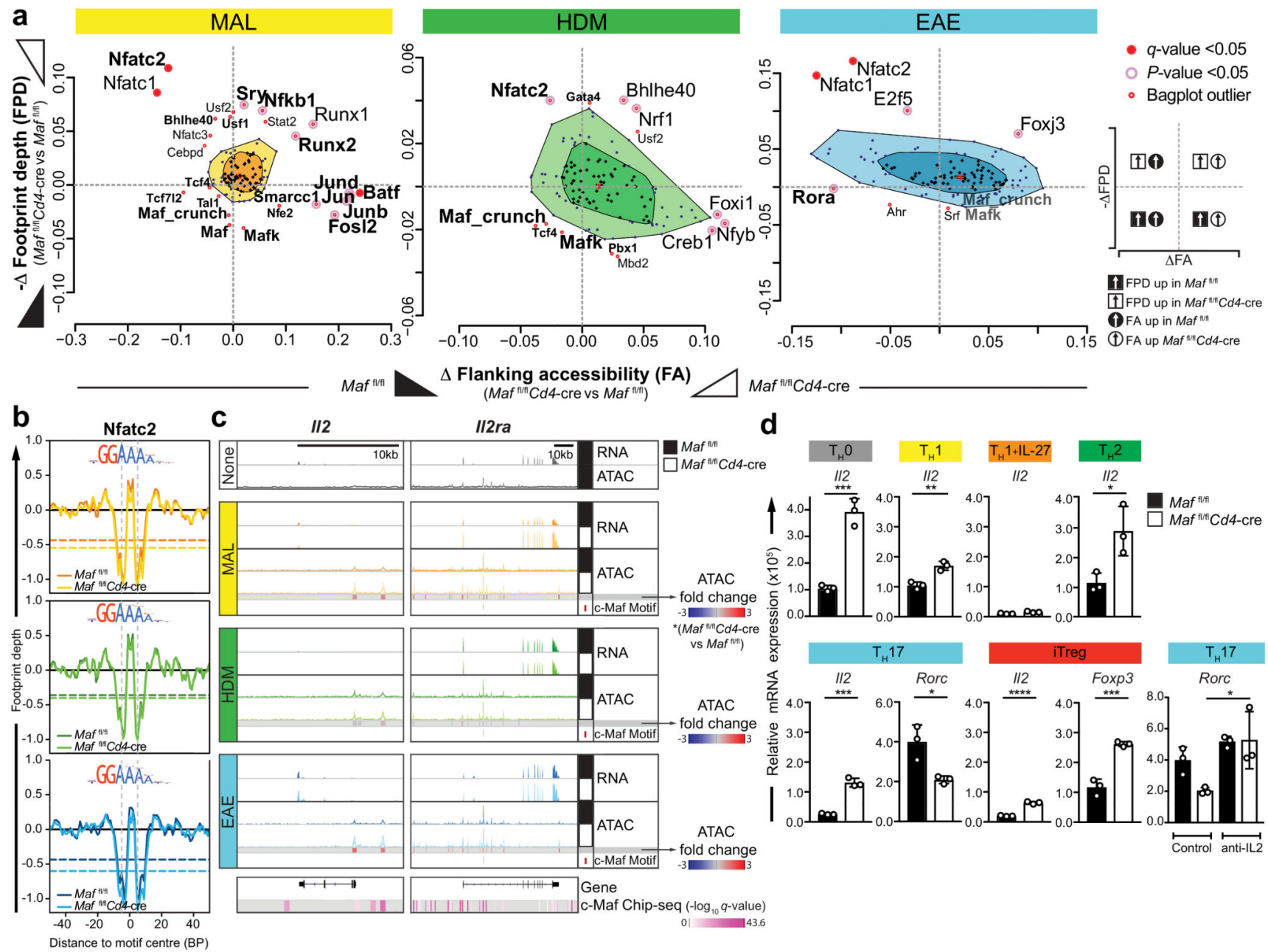

Figure 7. Identification and validation of IL-2 as a c-Maf target from inferred c-Maf regulated TF networks.

a, Bagplots depicting TFs with potential genome-wide changes in binding between CD4 ${ }^{+}$ $M a f^{f l / f l}$ and $M a f^{f l / f l} C d 4$-cre within ATAC-seq peaks in CD4 ${ }^{+}$T cells, as detected using the BaGFoot software. $P$-values in the key of the figure refer to the statistical confidence assigned to the differntial binding of a TF in each disease model ( $n=3$ independent animals (malaria) or biologically independent samples (HDM and EAE) per genotype), see Supplementary Data). Labelled in bold are TFs whose motif is enriched in the accessible genomic neighbourhood of differentially expressed genes (one-tailed Fisher's exact test qvalue < 0.05). b, Metaprofiles of ATAC-seq footprints containing an Nfatc2 motif match, in $\mathrm{CD}^{+}{ }^{+} \mathrm{Maf}^{\mathrm{f} / \mathrm{fl}}$ and $\mathrm{Maf} \mathrm{fl}^{\mathrm{fl} / \mathrm{fl}} \mathrm{Cd} 4$-cre T cells from malaria (yellow/orange), HDM allergy (light/ dark green) and EAE (light/dark blue). Coloured dashed lines represent the sum of Tn5 insertions across the footprint region in each condition. Vertical dashed lines represent the motif boundaries. c, Genome browser tracks of read coverage of RNA-seq and ATAC-seq in $\mathrm{CD}^{+} \mathrm{T}$ cells from the different disease models (shown as an overlay of $\mathrm{n}=3$ independent animals (malaria) or biologically independent samples (HDM and EAE) per genotype) as compared to untreated control and matched to c-Maf ChIP-seq and motif sites. d, Naive 
$\mathrm{CD}^{+} \mathrm{T}$ cells from $M a f^{f l / f l}$ and $M a f^{f l / f l} C d 4$ cre mice were differentiated in vitro and assessed for the expression of II2, Rorc and Foxp3 relative to Hprt (mean \pm SD; * $P<0.05$, ** $P<$ 0.01 , *** $P<0.001$, **** $P<0.0001$, unpaired $t$-test, two-tailed); $\mathrm{T}_{\mathrm{H}} 17$ cells were differentiated in vitro and assessed for the expression of Rorc in the presence or absence of anti-IL-2 ( $\mathrm{n}=3$ culture wells per condition, mean $\pm \mathrm{SD} ; * P<0.05$, one-way ANOVA). Representative data from three (or two, Th2) independent experiments are shown. 